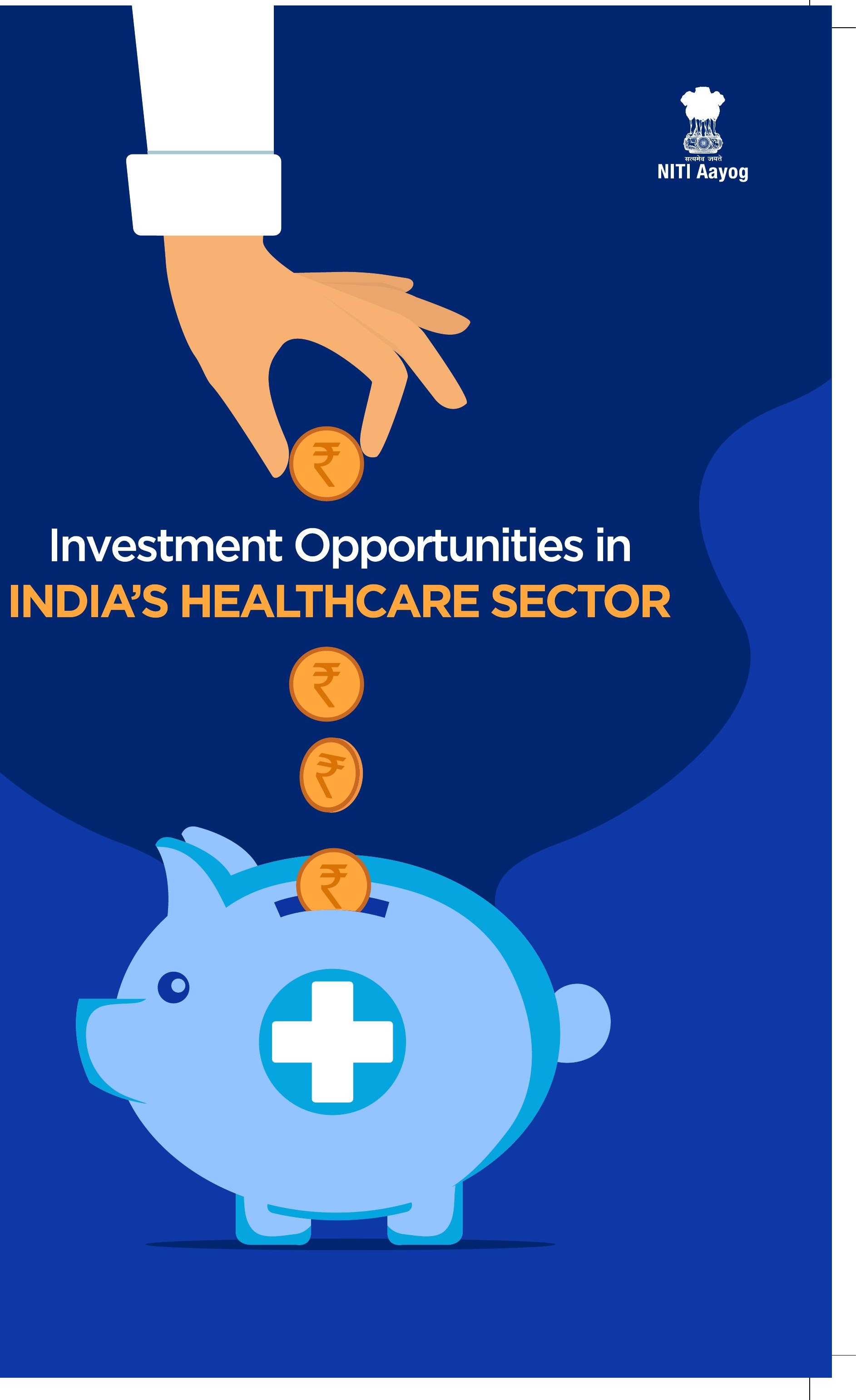




\title{
Investment Opportunities in India's Healthcare Sector
}

\author{
Publishing Agency: NITI Aayog
}

Year of Publication: 2021

Book, English

ISBN : 978-81-949510-8-7

Citation: Sarwal R; Prasad U; Madangopal K; Kalal S; Kaur D; Kumar A; Regy P; Sharma J. Investment Opportunities in India's

Healthcare Sector. NITI Aayog. March 2021. 


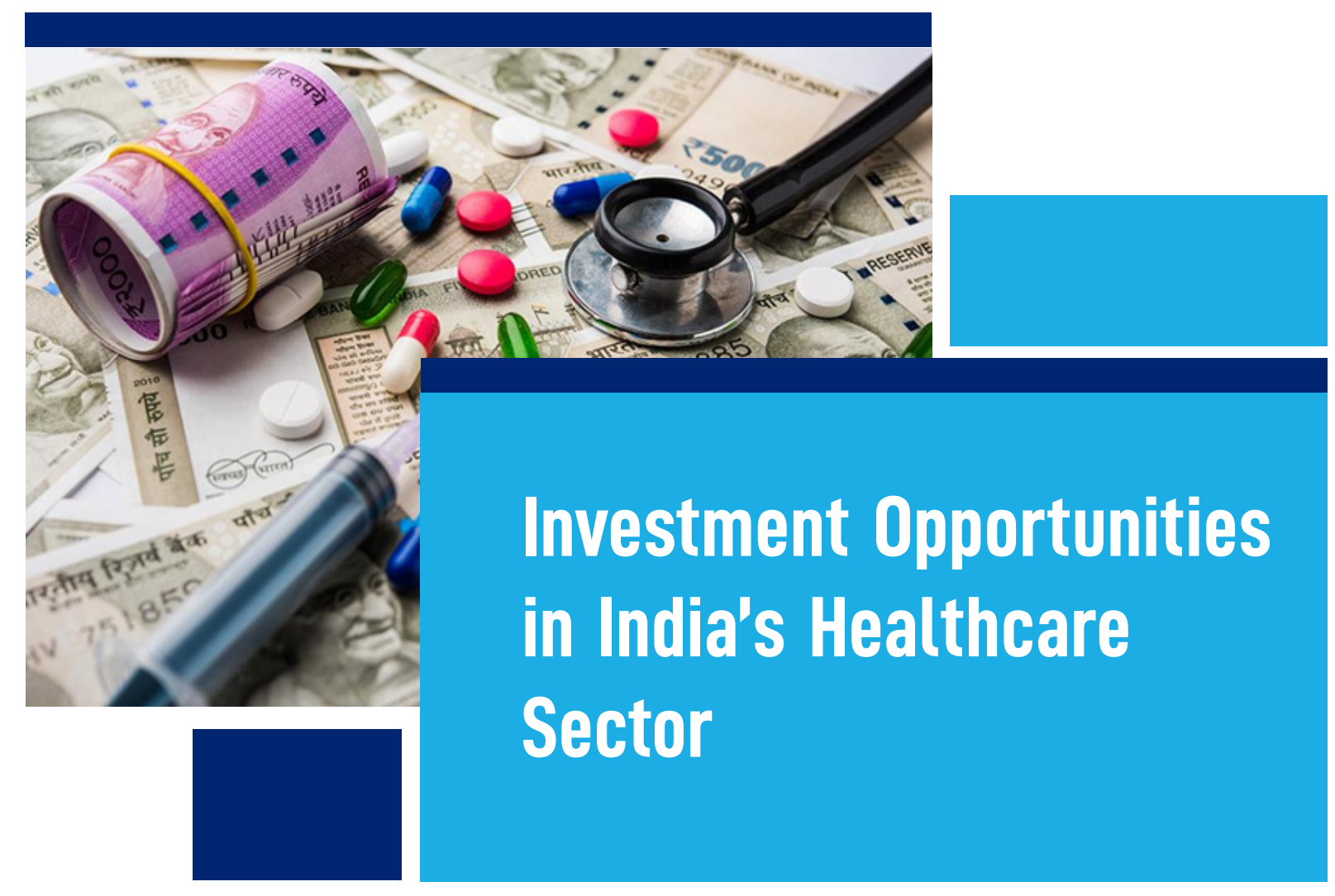




\section{FOREWORD}

Healthcare has become one of the largest sectors of the Indian economy, in terms of both revenue and employment. It has been growing at a CAGR of 22\% since 2016, employing 4.7 Million people directly. The sector has the potential to generate 2.7 million additional jobs in India between 2017-22 -- over 500,000 new jobs per year.

Several factors are driving the growth of the Indian healthcare sector including an aging population, a growing middle class, the rising proportion of lifestyle diseases, an increased emphasis on public-private partnerships as well as accelerated adoption of digital technologies, including telemedicine, besides heightened interest from investors and increased FDI inflows over the last two decades.

The Indian Government has undertaken deep structural and sustained reforms to strengthen the healthcare sector and has also announced conducive policies for encouraging FDI. The Aatmanirbhar Bharat Abhiyaan packages include several short-term and longer-term measures for the health system, including Production-Linked Incentive (PLI) schemes for boosting domestic manufacturing of pharmaceuticals and medical devices. Additionally, India is working towards becoming a hub for spiritual and wellness tourism, as the country has much to offer in Ayurveda and Yoga.

The COVID-19 pandemic has not only presented challenges but also several opportunities for India to grow. The crisis has opened the flood gates for Indian start-ups, many of whom have risen to the occasion and accelerated the development of low-cost, scalable, and quick solutions. Further, the pandemic is providing an impetus to the expansion of telemedicine and the home healthcare market in the country.

All these factors, together, make India's healthcare industry ripe for investment. In the hospital segment, the expansion of private players to Tier 2 and Tier 3 locations, beyond metropolitan cities, offers an attractive investment opportunity. India also has the opportunity to boost domestic manufacturing of pharmaceuticals, supported by the recent PLI schemes, alongside offering investment avenues in segments like contract manufacturing and research, over-thecounter drugs, and vaccines. India is also a land of opportunities for players in the medical devices industry, with tremendous opportunities for expansion of diagnostic and pathology centres as well as miniaturised diagnostics.

In the first section, this Report provides an overview of India's healthcare sector, including insights about its employment generation potential, the prevailing business and investment climate as well as the overarching policy landscape. The second section highlights the key drivers of growth for the sector and the third section elaborates upon the enabling policies and investment opportunities in 7 key segments, including hospitals and infrastructure, health insurance, pharmaceuticals and biotechnology, medical devices, medical tourism, home healthcare as well as telemedicine and other technology-related health services. 
This Report was prepared under the overall guidance and leadership of Dr. Rajiv Kumar, Vice Chairman; Dr. Vinod K. Paul, Member (Health) and Dr. Rakesh Sarwal, Additional Secretary, NITI Aayog. The compilation was put together by Urvashi Prasad with contributions from Dr. K. Madan Gopal, Shoyab Ahmed Kalal, Deepjyot Kaur, Anurag Kumar, Prashanth V. Regy, and Dr. Jitendra Sharma. I hope readers will find this to be a comprehensive repository of information about the wide array of investment opportunities in India's healthcare sector.

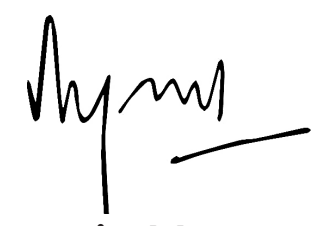

Amitabh Kant

CEO, NITI Aayog 


\section{ABBREVIATIONS}

PLI

NDHM

NSDC

A

CAGR

HIT

HWC

PM-JAY

MLP

IPO

PE

NCD

MARB

R\&D

MVT

VGF

MCA

IIG

IRDAI

FDA

WHO-GMP

API

OOPE

PMBJP

NIPERS

KSMs

Dis
Production-Linked Incentive

National Digital Health Mission

National Skill Development Corporation

Artificial Intelligence

Compound Annual Growth Rate

Health Information Technology

Health and Wellness Centre

Pradhan Mantri Jan Aarogya Yojana

Mid-Level Provider

Initial Public Offering

Private Equity

Non-Communicable Disease

Medical Assessment and Rating Board

Research and Development

Medical Value Trave

Viability Gap Funding

Model Concession Agreement

India Investment Grid

Insurance Regulatory and Development Authority of India

Food and Drug Administration

World Health Organisation-Good Manufacturing Practices

Active Pharmaceutical Ingredient

Out-Of-Pocket Expenditure

Pradhan Mantri Bhartiya Janaushadhi Pariyojana

National Institutes of Pharmaceutical Education \& Research

Key Starting Materials

Drug Intermediaries 


$\begin{array}{ll}\text { IVDS } & \text { In-vitro Diagnostic Devices } \\ \text { BIRAC } & \text { Biotechnology Industry Research Assistance Council } \\ \text { DBT } & \text { Department of Biotechnology } \\ \text { MSMEs } & \text { Micro Small \& Medium Enterprises } \\ \text { MoHFW } & \text { Ministry of Health \& Family Welfare } \\ \text { AMTZ } & \text { Andhra Pradesh MedTech Zone } \\ \text { JCI } & \text { Joint Commission International } \\ \text { NABH } & \text { National Accreditation Board for Hospitals \& Healthcare Providers } \\ \text { FTAS } & \text { Foreign Tourist Arrivals } \\ \text { GST } & \text { Goods and Services Tax } \\ \text { E-UPHC } & \text { Electronic Urban Primary Healthcare Centre }\end{array}$




\section{CONTENTS}

EXECUTIVE SUMMARY

IX

\begin{tabular}{ll} 
& \\
\hline & \\
OVERVIEW OF HEALTHCARE INDUSTRY & 1 \\
$1.1 \quad$ EMPLOYMENT GENERATION POTENTIAL OF HEALTH SECTOR & 2 \\
1.2 BUSINESS AND INVESTMENT CLIMATE & 4 \\
1.3 OVERARCHING POLICY LANDSCAPE & 5 \\
1.3.1 AYUSHMAN BHARAT & 5 \\
1.3.2 HUMAN RESOURCES FOR HEALTH & 6 \\
1.3.3 NATIONAL DIGITAL HEALTH MISSION (NDHM) & 6 \\
1.3.4 FOREIGN DIRECT INVESTMENT & 6 \\
1.3.5 TAX INCENTIVES & 7 \\
1.3.6 HEALTH DIPLOMACY & 7
\end{tabular}

DRIVERS OF GROWTH

2.1 DEMOGRAPHIC, EPIDEMIOLOGICAL AND HEALTH TRANSITIONS 9

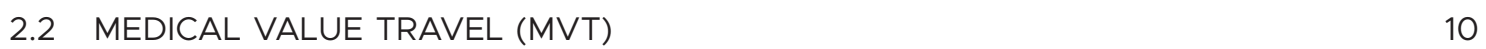

$\begin{array}{lll}2.3 & \text { ENABLING POLICY ENVIRONMENT } & 10\end{array}$

$\begin{array}{lll}2.4 & \text { DEMAND-SUPPLY GAP } & 10\end{array}$

2.5 OTHER FACTORS 11

KEY SEGMENTS OF HEALTHCARE INDUSTRY

3.1 HOSPITALS AND INFRASTRUCTURE 12

3.1.1 SPECIFIC ENABLING POLICIES 
3.1.2 INVESTMENT OPPORTUNITIES

3.2 HEALTH INSURANCE

3.2.1 SPECIFIC ENABLING POLICIES

3.2.2 INVESTMENT OPPORTUNITIES

3.3 PHARMACEUTICALS AND BIOTECHNOLOGY 15

3.3.1 SPECIFIC ENABLING POLICIES 16

3.3.2 INVESTMENT OPPORTUNITIES 19

3.4 MEDICAL DEVICES, EQUIPMENT AND DIAGNOSTICS 19

3.4.1 SPECIFIC ENABLING POLICIES

3.4.2 INVESTMENT OPPORTUNITIES $\quad 22$

3.5 MEDICAL VALUE TRAVEL 22

3.5.1 SPECIFIC ENABLING POLICIES

3.5.2 INVESTMENT OPPORTUNITIES

3.6 HOME HEALTHCARE $\quad 25$

3.6.1 INVESTMENT OPPORTUNITIES 26

3.7 TELEMEDICINE AND OTHER TECHNOLOGY-RELATED HEALTH SERVICES 26

3.7.1 SPECIFIC ENABLING POLICIES 26

$\begin{array}{ll}\text { 3.7.2 INVESTMENT OPPORTUNITIES } & 27\end{array}$ 


\section{EXECUTIVE SUMMARY}

India's healthcare industry has been growing at a Compound Annual Growth Rate of around $22 \%$ since 2016. At this rate, it is expected to reach USD 372 Billion in 2022. Healthcare has become one of the largest sectors of the Indian economy, in terms of both revenue and employment. In 2015, the healthcare sector became the fifth largest employer, employing 4.7 Million people directly. As per estimates by the National Skill Development Corporation (NSDC) healthcare can generate 2.7 Million additional jobs in India between 2017-22 -- over 500,000 new jobs per year.

India's healthcare industry comprises hospitals, medical devices and equipment, health insurance, clinical trials, telemedicine and medical tourism. These market segments are expected to diversify as an ageing population with a growing middle class increasingly favours preventative healthcare. Moreover, the rising proportion of lifestyle diseases caused by high cholesterol, high blood pressure, obesity, poor diet and alcohol consumption in urban areas is boosting demand for specialised care services.

In addition to these demographic and epidemiological trends, COVID-19 is likely to catalyse long-term changes in attitudes towards personal health and hygiene, health insurance, fitness and nutrition as well as health monitoring and medical check-ups. The pandemic has also accelerated the adoption of digital technologies, including telemedicine.

Further, there is a growing emphasis on and emergence of Public-Private Partnership models in India's healthcare sector. The country's relative cost competitiveness and availability of skilled labour are also making it an increasingly favoured destination for Medical Value Travel.

On the policy front, the Indian Government is undertaking deep structural and sustained reforms to strengthen the healthcare sector; it has also announced conducive policies for encouraging Foreign Direct Investment (FDI). In fact, India's FDI regime has been liberalised extensively. Currently, FDI is permitted up to $100 \%$ under the automatic route (i.e., the nonresident investor or Indian company does not require approval from the Government of India for the investment) in the hospital sector and in the manufacture of medical devices. In the pharmaceutical sector, FDI is permitted up to $100 \%$ in greenfield projects and $74 \%$ in brownfield projects under the automatic route.

India has emerged as one of the fastest-growing emerging economies over the last two decades, receiving large FDI inflows, which have grown from USD 2.5 Billion in 2000-01 to USD 50 Billion in 2019-20. The healthcare sector, in particular, has received heightened interest from investors over the last few years, with the transaction value increasing from USD 94 Million (2011) to USD 1,275 Million (2016) - a jump of over 13.5 times.

All of these factors together create several opportunities for investment in India's healthcare industry. 
In the hospital segment, the expansion of private players to Tier 2 and Tier 3 locations, beyond metropolitan cities, offers an attractive investment opportunity. According to Invest India's Investment Grid, there are nearly 600 investment opportunities worth USD 32 Billion (INR 2.3 Lakh Crore) in the country's hospital/medical infrastructure sub-sector.

With respect to pharmaceuticals, India has the opportunity to boost domestic manufacturing, supported by recent Government schemes with performance-linked incentives, as part of the Aatmanirbhar Bharat (Self-Reliant India) initiative. Further, between 2018 and 2024, patents worth USD 251 Billion are expected to expire globally, presenting a lucrative opportunity for the country's pharmaceutical sector, including the patent market. In addition to generic drugs, there are investment opportunities in other segments of India's pharmaceutical sector, including over-the-counter drugs, vaccines and contract manufacturing and research.

In the medical devices and equipment segment, expansion of diagnostic and pathology centres as well as miniaturised diagnostics have high potential for growth. Medical Value Travel, especially wellness tourism, also has bright prospects, given India's inherent strengths in alternative systems of medicine.

While the adoption of home healthcare solutions in India is currently at a relatively nascent stage, it has tremendous potential for growth in the future on account of the rising elderly population in the country, increase in the incidence of chronic diseases, enhanced demand for constant personalised care as well as the emergence of nuclear family structures in urban areas.

Lastly, technology advancements such as Artificial Intelligence (Al), wearables and other mobile technologies, along with Internet of Things, offer several avenues for investment. Key segments where new opportunities are likely to emerge for health technology players in the near future include development of tools to facilitate emergency care and improvements to medical infrastructure, through technology-based optimization. This includes expanding the scope of wearable devices to track health conditions, developing patient-facing mobile health applications as well as greater integration of Al, robots, and blockchain technologies. 


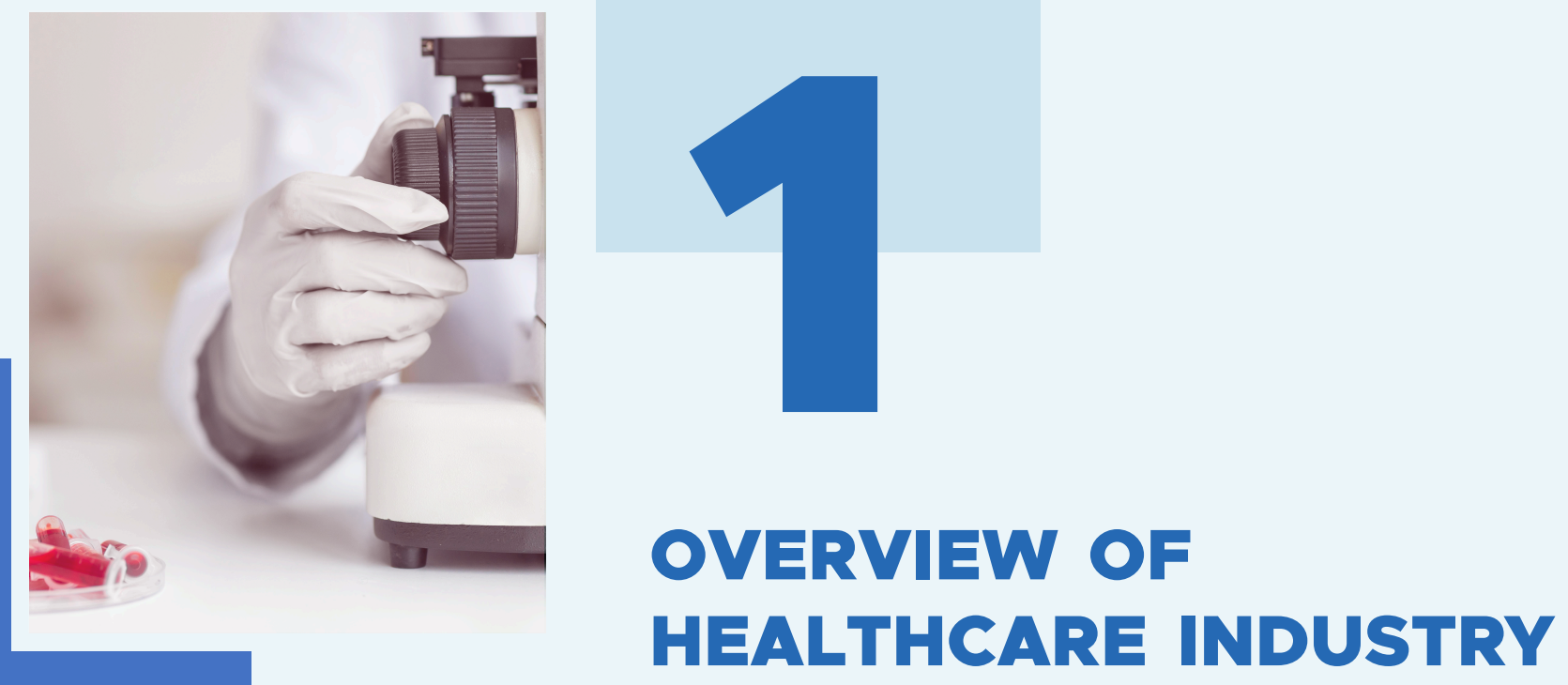

India's healthcare industry comprises hospitals, medical devices and equipment, health insurance, clinical trials, telemedicine and medical tourism.
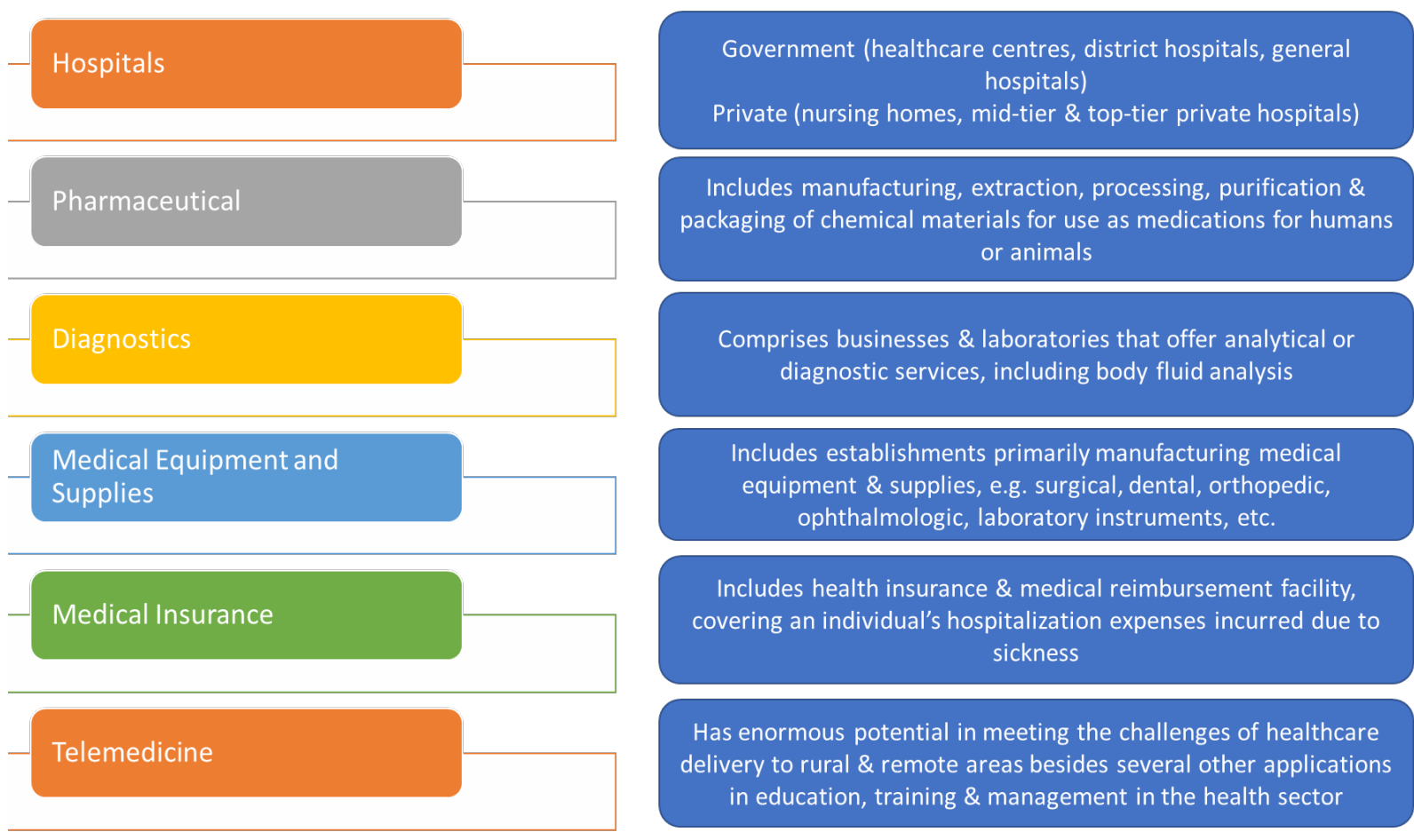

Comprises businesses \& laboratories that offer analytical or diagnostic services, including body fluid analysis

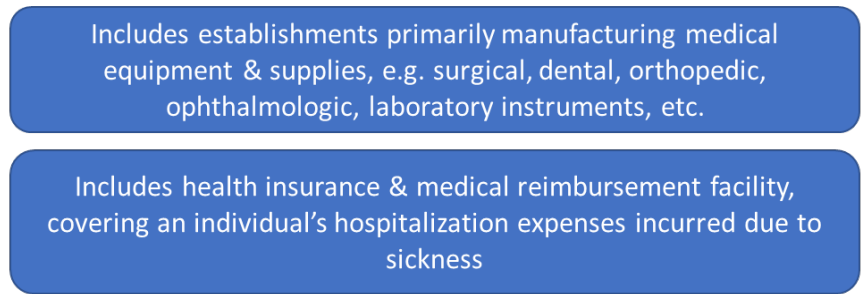

Has enormous potential in meeting the challenges of healthcare delivery to rural $\&$ remote areas besides several other applications in education, training \& management in the health sector

Figure 1: Major Segments in India's Healthcare Sector'

The country's healthcare sector has grown rapidly over the last 5 years, in particular, with a Compound Annual Growth Rate (CAGR) of approximately 22\% since 2016. ${ }^{1}$ Healthcare has become one of the largest sectors of the Indian economy, in terms of both revenue and employment.

1 Healthcare. India Brand Equity Foundation. Retrieved December 15, 2020 from https://www.ibef.org/download/Healthcare July-2019. pdf. 


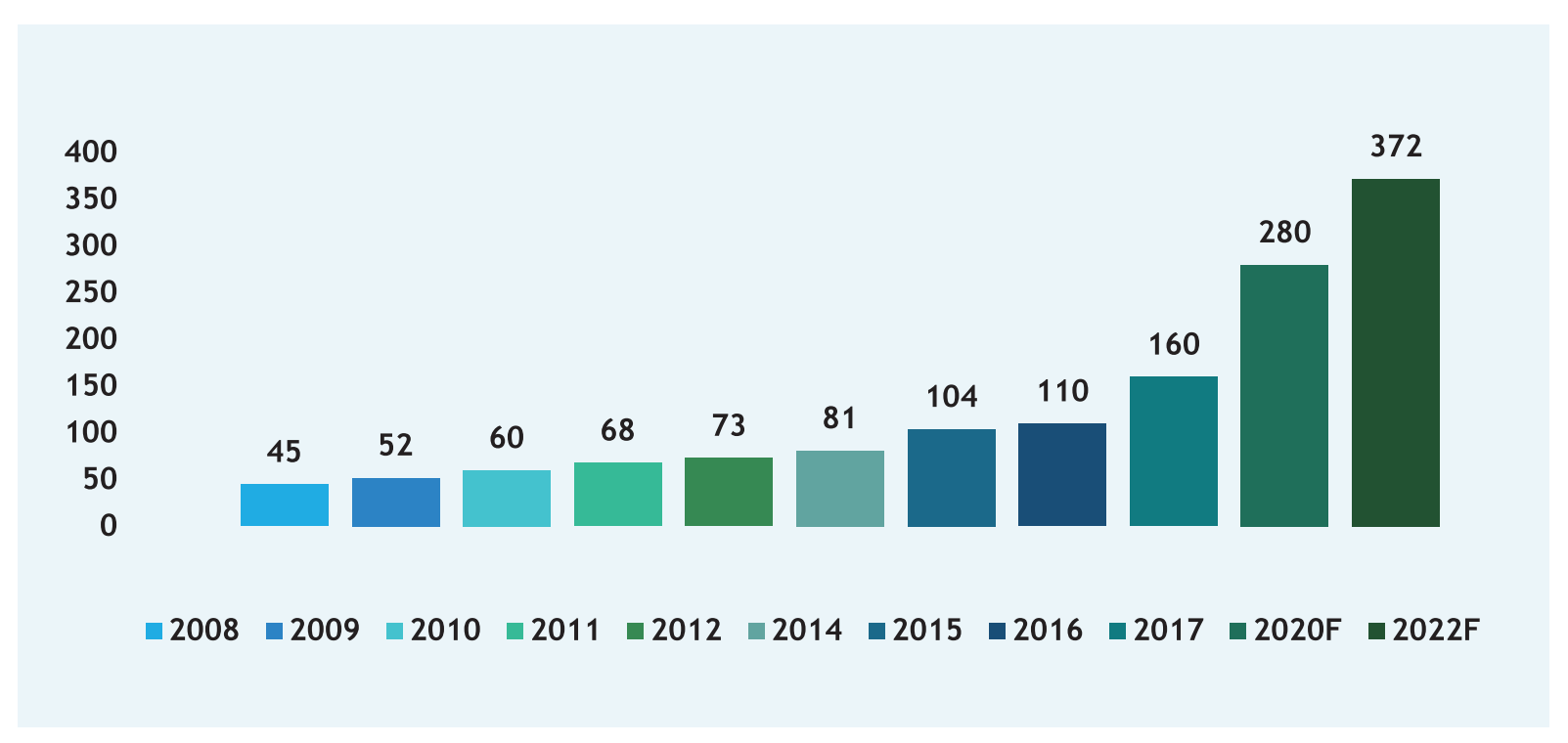

Figure 2: Growth Trend of India's Healthcare Sector (USD Billion)²

Note: Compound Annual Growth Rate (2008-2022): 16.28\%

\subsection{EMPLOYMENT GENERATION POTENTIAL OF HEALTH SECTOR}

Rapid and sustained growth over the last few years has created large employment opportunities in India's health sector. A report by KPMG and FICCI shows that the healthcare sector became the fifth largest employer in 2015, employing 4.7 Million people directly. The NSDC estimates that the health sector will directly employ around 7.5 Million people by 2022, adding approximately 2.7 Million new jobs between 2017-22 -- over 500,000 new jobs per year. ${ }^{2}$

Beyond the direct impact on jobs and economic growth, the healthcare sector's employment patterns have additional multiplier effects and distributional benefits. First, the health sector can boost India's female labour force participation since it employs a large number of women. In fact, the final report of WHO's High-Level Commission on Health Employment and Economic Growth (2016) specifically highlights the employment potential of the health sector for women. ${ }^{3}$

Second, the health sector also generates additional jobs and economic activity indirectly i.e., in the non-health sector. The same report by WHO suggests that each dollar spent in the health sector results in an additional USD 0.77 contribution to economic growth as a result of indirect and induced effects. ${ }^{3}$ These effects include establishing infrastructure and facilities, purchasing equipment as well as building skills through education and training which, in turn, translate into direct manufacturing and services outputs, leading to more jobs.

2 Healthcare. Invest India. https://www.investindia.gov.in/sector/healthcare. 


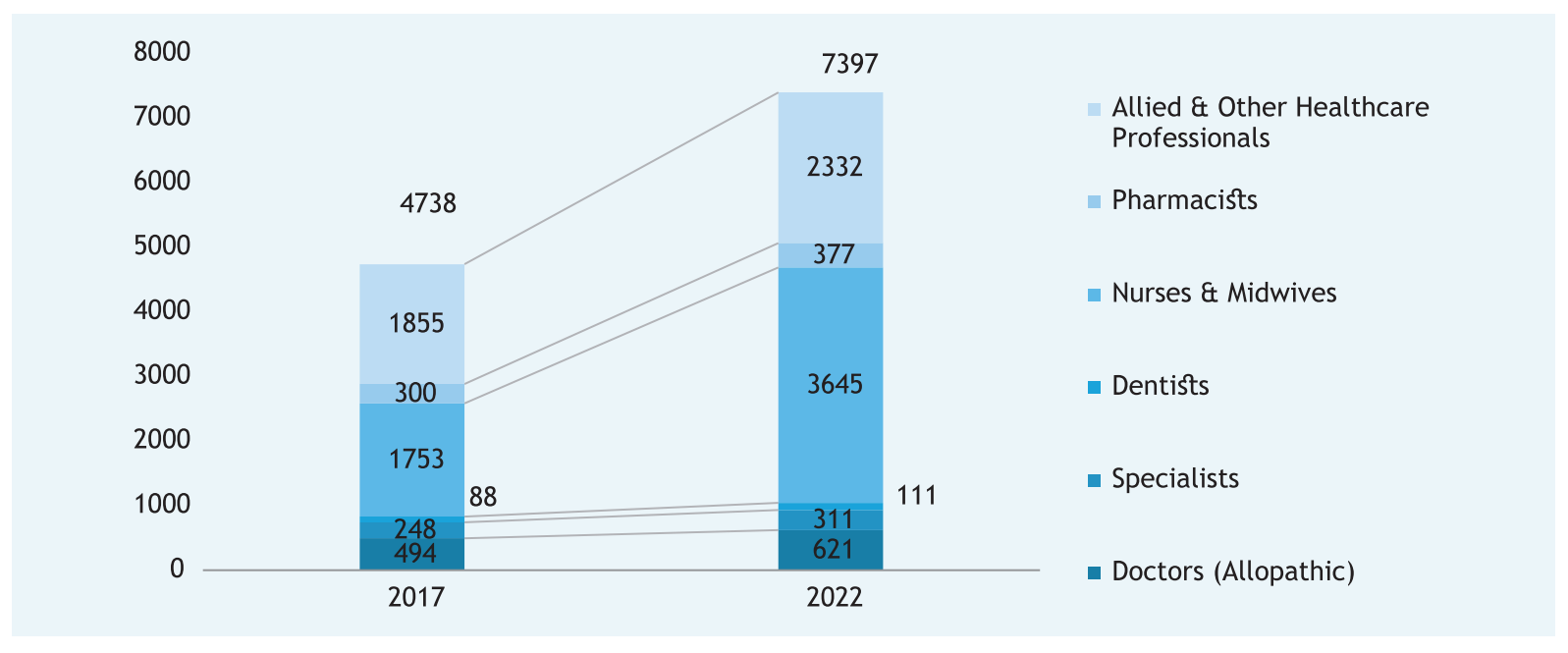

Figure 3: Direct Jobs in India's Healthcare Sector, 2017 - 2022 Expected (in thousands) ${ }^{3}$

Note: The 2022 estimates for nurses and midwives may be high given the limited capacity to train and deploy an additional 1.9 Million nurses and midwives in a 5-year period.

Further, growth in insurance and digitization of the healthcare sector in India will generate additional jobs. Under the National Digital Health Mission (NDHM), for instance, personnel will be required for digitization of family records from the community to the facility level. Human capacity, specifically personnel skilled in fields such as HIT (Health Information Technology), Health Informatics and Medical Informatics (sometimes called Clinical Informatics), is required to support such initiatives. ${ }^{4}$

Third, the launch of Ayushman Bharat in 2018 has generated additional avenues for job creation. Each of the 150,000 Health and Wellness Centres (HWCs) proposed to be established under the program will be managed by a team comprising a Mid-Level Health Provider (MLP) along with ANMs, ASHAs and a male health worker. ${ }^{5}$ Approximately 150,000 skilled and independently certified MLPs will therefore be required to manage the HWCs.

The other pillar of Ayushman Bharat, the Pradhan Mantri Jan Arogya Yojana (PM-JAY), has initiated the transition towards demand-side financing and strategic purchasing. ${ }^{6}$ Over time, expansion of PM-JAY, and a greater focus on improving health insurance coverage in general, will also generate new jobs as it requires supporting capacity building for purchasers (health insurance agencies) and healthcare providers alike. Other types of jobs that will be created through the expansion of insurance programs include actuaries for modelling public spending, coders, and data analysts. Such roles are critical for enabling implementation of strategic purchasing contracts as well as detecting fraud.

Ayushman Bharat initiatives will also give an impetus to the training of nurses and allied health professionals for delivery of skilled support services in secondary and tertiary care.

Finally, the expected rapid growth of India's home healthcare market can also increase job opportunities significantly. ${ }^{7}$ Home healthcare, after all, is a labour-intensive industry, with the potential to create as many as 200,000 blue collar jobs annually across 50 cities in India. ${ }^{8}$ The industry can employ large numbers of skilled patient attendants and caregivers, including from rural areas. It can also create as many as 50,000 jobs for women annually, in nursing as well as attendant/caregiver roles. ${ }^{8}$

3 Human Resource and Skill Requirements in the Healthcare Sector. NSDC, Ministry of Skill Development \& Entrepreneurship, Government of India. Retrieved January 5, 2021 from https://skillsip.nsdcindia.org/knowledge-products/human-resource-and-skill-requirements-health-sector. 


\subsection{BUSINESS AND INVESTMENT CLIMATE}

India improved its Ease of Doing Business ranking from 142 in 2014 to 63 in 2019, a jump of 79 positions. ${ }^{1}$ India has also been ranked number 1 in the Central and South Asian region in the Global Innovation Index, an improvement of 33 positions, from number 81 globally in 2015 to number 48 in $2020{ }^{1}$

India has been one of the fastest-growing emerging economies over the last two decades, receiving large FDI inflows, which have grown from USD 2.5 Billion in 2000-01 to USD 50 Billion in 2019-20. ${ }^{1}$ In health, FDI has been concentrated in pharmaceuticals, constituting approximately two-thirds of the total health-sector-related FDI over the last two decades. ${ }^{9}$ Thus, there is considerable scope for more FDI in the medical devices manufacturing segment, in particular, for discouraging import dependency.

Table 1: FDI in India's Health Sector (2000-2020)4

\begin{tabular}{|l|c|}
\hline \multicolumn{1}{|c|}{ Health-related FDI (USD Million) } & $\mathbf{2 5 , 3 5 7}$ \\
\hline Drugs \& Pharmaceuticals & 16,501 \\
\hline Hospital \& Diagnostic Centres & 6,727 \\
\hline Medical \& Surgical Appliances & 2,130 \\
\hline
\end{tabular}

The healthcare sector has received heightened interest from investors (venture capital and private equity) over the last few years, with the transaction value increasing from USD 94 Million (2011) to USD 1,275 Million (2016) - a jump of over 13.5 times., ${ }^{9,10}$ Initial Public Offerings (IPOs) of 4 major companies, Dr Lal PathLabs, HCG, Narayana Hrudayalaya and Thyrocare were oversubscribed, reinforcing investor confidence in the sector. ${ }^{9,10}$ A slew of investments by global health players, including the Parkway Group and a host of players from the Middle East, have strengthened the perception of India as an attractive healthcare investment destination.

Table 2: Select Private Equity Deals in Healthcare Industry Over the Last Few Years ${ }^{5}$

\begin{tabular}{|l|c|c|c|}
\hline \multicolumn{1}{|c|}{ Company } & $\begin{array}{c}\text { Amount (USD } \\
\text { Million) }\end{array}$ & Sector & Investors \\
\hline Radiant Life Care & 200 & Hospitals & KKR \\
\hline Condis Healthcare & 200 & Hospitals & India Value Fund \\
\hline Manipal Health Enterprises & 171 & Hospitals & Temasek \\
\hline Max Healthcare Institute & 75 & Hospitals & IFC \\
\hline Paras Healthcare & 43 & Hospitals & Creador Capital \\
\hline Healthcare at Home & 40 & Home healthcare & Quadria India \\
\hline Portea Medical & 26 & Home healthcare & IFC, Accel India, Sabre \\
\hline
\end{tabular}

4 Note on Health and Pharmaceutical Sector. Invest India.

5 Funding Indian healthcare: Catalysing the next wave of growth. PwC India. Retrieved December 16, 2020 from https://www.pwc.in/ publications/2017/funding-indian-healthcare-catalysing-the-next-wave-of-growth.html.

Financing and Funding Indian Healthcare: Navigating the Turbulent Tide. PwC India. Retrieved December 16, 2020 from https://www. pwc.in/assets/pdfs/publications/2018/financing-and-funding-indian-healthcare-navigating-the-turbulent-tide.pdf. 
Growth in multi-specialty and single-specialty hospitals in the country has taken place mainly on the back of private equity (PE) funding. A flurry of investments happened post the year 2000, mainly from overseas funds, when India allowed 100\% FDI in the hospital sector. ${ }^{9,10}$ Till 2019, more than 110 PE and Venture Capital investors had invested in the healthcare delivery space in India..$^{10}$ The value of merger and acquisition deals in hospitals jumped by a record 155\% to INR 7,615 Crore (USD 1.09 Billion) in FY19.11

\subsection{OVERARCHING POLICY LANDSCAPE}

India is committed to achieving Universal Health Coverage as part of the Sustainable Development Goals. In the Union Budget 2021-22, the Government allocated a sum of INR 2,23,846 Crore for health and wellbeing, up from the 2020-21 budgetary allocation of INR 94,452 Crore. ${ }^{12}$ Between FY15-FY21 BE, India's public health expenditure as a percentage of GDP increased from $1.2 \%$ to $1.8 \% .^{12}$

India's National Health Policy (2017) aims to increase Government spending on health to $2.5 \%$ of GDP by $2025 . .^{13}$ The Policy emphasises greater investment in preventative and primary healthcare; access to and financial protection at the secondary and tertiary care levels as well as the provision of free drugs, diagnostics and emergency care services at all public hospitals. Further, the Policy envisages private sector collaboration, including the use of financial and non-financial incentives to encourage participation.

\subsubsection{AYUSHMAN BHARAT}

The Indian Government has undertaken several major reform efforts to strengthen the healthcare sector over the last few years. The flagship initiative of the Government, Ayushman Bharat, for instance, seeks to comprehensively strengthen the health system right from the primary level to tertiary care, thereby signalling a marked shift in focus from the implementation of vertical health programs. Its first dimension is focused on building the next generation primary healthcare system through a network of HWCs to promote good health as well as detect diseases early, which is especially critical in the context of India's rising non-communicable disease (NCD) burden. As of 23 February, 2021, 60,520 HWCs were operational in India. ${ }^{5}$

Increased focus on disease prevention and extensive screening for diseases at the primary care level through HWCs are long-term, sustainable solutions for reducing the disease burden and consequently out-of-pocket expenditure on health.

Currently, out-of-pocket expenditure constitutes more than $60 \%$ of all health expenses, a major challenge in a country like India where a large segment of the population is poor. ${ }^{15}$ It is estimated that approximately 63 Million people fall into poverty every year due to lack of financial protection for their healthcare needs. ${ }^{14}$ In order to address this important challenge, India launched the PM-JAY, the second important pillar of the Ayushman Bharat initiative. ${ }^{6}$ PM-JAY is the world's largest non-contributory Government-sponsored health insurance scheme that enables increased access to inpatient healthcare for poor and vulnerable families in secondary and tertiary facilities. It could be a crucial inflexion point for the healthcare industry in India because of its emphasis on improving the performance of public facilities and leveraging the potential of the private sector in delivering healthcare for the poor. The scheme provides 500 Million beneficiaries with an annual hospitalisation cover of up to INR 500,000 per family. ${ }^{6}$ Over 24,000 hospitals have been empanelled under the scheme, as of 23 February, 2021 and over 16 Million hospital admissions have been covered. ${ }^{6}$ By providing drugs and diagnostics free of cost at the HWCs as well as covering most secondary and tertiary procedures under PM-JAY, Ayushman Bharat has the potential to protect millions. 


\subsubsection{HUMAN RESOURCES FOR HEALTH}

Medical education has been another important area of reform for the Government over the last few years, with a complete overhauling of the regulatory architecture in Modern Medicine, Indian Systems of Medicine (Ayurveda, Yoga) and Homeopathy. The objective of these reform efforts is to ensure uniform standards of medical education, create a curriculum relevant to the Indian context and improve the doctor-population ratio in the country. ${ }^{15}$ The National Medical Commission Act 2019, which replaced the Medical Council of India, includes a provision for a Medical Assessment and Rating Board (MARB), which will rate institutions on the quality of education/training imparted. ${ }^{15}$ Similar reforms are also envisaged in nursing, dentistry and allied health fields.

In addition to reforming the governance mechanisms for medical education in the country, the Government is also expanding the number of medical and nursing colleges for meeting the demand for health professionals. ${ }^{14}$ In November 2020, the number of medical colleges in India increased to over 560 from 412 in FY16. ${ }^{16}$ Further, the Government is implementing a scheme for establishing medical colleges attached with district hospitals. The number of registered medical doctors increased to 1,255,786 in September 2020 from 827,006 in 2010.16

\subsubsection{NATIONAL DIGITAL HEALTH MISSION (NDHM)}

In his address to the nation on India's 74th Independence Day, the Prime Minister announced the launch of the NDHM. ${ }^{4}$ The Mission aims to create a management mechanism to process digital health data and facilitate its seamless exchange; develop registries of public and private facilities, health service providers, laboratories and pharmacies; and support clinical decisionmaking as well as offer services like telemedicine. NDHM has the potential to make the health system more evidence based, transparent and efficient.

The digitisation push by the Government will not only enable patients to share their health profiles with providers for treatment and monitoring purposes, but also access accurate information about the credentials and pricing of services offered by various health facilities, providers and diagnostic laboratories. It is anticipated that over the next 10 years, an incremental economic value of over USD 200 Billion can be unlocked for the health sector through rigorous implementation of the NDHM. ${ }^{17}$ Three major shifts can enable this: greater demand for health services, especially seeking early care for NCDs; improvement in quality of care enabled by digital health (shift from volume-based to value-based healthcare), and streamlining of multistakeholder processes and interactions through use of an integrated health data system. All of these elements together will lead to greater efficiency, cost savings and ultimately improve health outcomes and productivity.

\subsubsection{FOREIGN DIRECT INVESTMENT}

India's FDI regime has been liberalised extensively. Currently, FDI is permitted up to $100 \%$ under the automatic route (i.e., the non-resident investor or Indian company does not require approval from the Government of India for the investment) in the hospital sector and in the manufacture of medical devices. ${ }^{1}$ In the pharmaceutical sector, FDI is permitted up to $100 \%$ in greenfield projects and $74 \%$ in brownfield projects under the automatic route. ${ }^{1,18}$ FDI beyond 74\% in brownfield projects requires approval from the Foreign Investment Promotion Board.1,16 Between April 2000-June 2020, India received USD 6.8 Billion in FDI in hospitals and diagnostic centres. ${ }^{1}$ In the AYUSH sector as well, 100\% FDI is permitted for the wellness and medical tourism segment. ${ }^{16}$ 
Table 3: FDI Permitted in Various Healthcare-Related Sectors in India (By Route)6

\begin{tabular}{|c|c|c|}
\hline Sector & Automatic & Government \\
\hline Construction of Hospitals & $100 \%$ & \\
\hline Healthcare (Greenfield) & $100 \%$ & \\
\hline Healthcare (Brownfield) & Up to $74 \%$ & Above $74 \%$ \\
\hline Medical Devices & $100 \%$ & \\
\hline Biotechnology (Brownfield) & Up to $74 \%$ & Above $74 \%$ \\
\hline Biotechnology (Greenfield) & $100 \%$ & \\
\hline Pharmaceuticals (Brownfield) & Up to $74 \%$ & Above $74 \%$ \\
\hline Pharmaceuticals (Greenfield & $100 \%$ & \\
\hline Insurance (Intermediaries) & $100 \%$ & \\
\hline
\end{tabular}

\subsubsection{TAX INCENTIVES}

All healthcare education and training services are exempted from service tax. ${ }^{1,16}$ The tax holiday under section 80-IB for private healthcare providers operating 50-bedded (or more) hospitals in nonmetropolitan areas has been increased. The benefit of section 80-IB has also been extended to new hospitals with 100 beds or more set up in rural areas; such hospitals are entitled to $100 \%$ deduction on profits for 5 years. ${ }^{11}$

A $250 \%$ deduction for approved expenditure incurred on operating technology enables healthcare services such as telemedicine and remote radiology. ${ }^{1,16}$ Further, there is an income tax exemption for 15 years for domestically manufactured medical technology products.

\subsubsection{HEALTH DIPLOMACY}

With the incremental dismantling of established global value chains due to COVID-19 and the resultant local versions of "aatmanirbhar" emerging in several countries grappling with resource generation, government-to-government collaborations with individual nations or regional blocks on affordable and accessible healthcare services (medical value travel, telemedicine, tele-radiology) and products (medical devices of all categories) will lead to complementary and equitable globalization 2.0. This version of globalization is necessitated by the emerging socio-medico-economic situation post the COVID-19 pandemic, profiteering of old global value chains, inadequate/badly affected health infrastructure in developing and developed countries alike, economies of shared scale and a growing strategic need for health security ownership. India's diplomatic and emerging international clout can prove to be an important strength in this scenario. In particular, India's agreement with the block of 50 African nations (Lucknow Declaration) can be a good opportunity to co-create/collaborate as well as serve the captive markets alongside integrating health security into the overall national security agenda. ${ }^{19}$

India is steadily carving out a unique Indian healthcare story. ${ }^{20}$ It is one of the few developing countries that has developed unique solutions relevant to the entire global South. Medical tourism from its extended neighbourhood attests to this. Indian development partnership

6 Healthcare. India Brand Equity Foundation. Retrieved December 15, 2020 from https://www.ibef.org/download/Healthcare-July-2019. pdf.

Healthcare. Invest India. https://www.investindia.gov.in/sector/healthcare. 
is creating medical infrastructure such as hospitals, providing training and medical services, sometimes remotely through telemedicine, to its larger neighbourhood and in Africa.

A comprehensive health diplomacy which can leverage Indian strengths and match it to Indian requirements at the international level requires an ability to synthesize and blend the various international cooperation activities already being undertaken by different branches of Government. A "purpose-driven" and non-siloed approach to health diplomacy and structures that facilitate a 'whole-of-government' approach to this critical area are required.20 India will need to tap FDI and technology for the private sector which has an important role in our health sector. Further, upgradation of Indian healthcare research and development (R\&D) capacity is paramount if we are to transition into a knowledge economy. R\&D capacity is in turn dependent on funds which are channelled in accordance with agendas that are fashioned by globally influential players including multilateral bodies, global health initiatives, pharma companies, academic institutions and non-state actors. India needs to project its priorities on this global stage to ensure that its pressing problems are factored into these discussions. Indian priorities include antimicrobial resistance, studies on pathogens, vaccine technologies, biotherapeutics, technologies for antibodies, diagnostics technologies, early warning systems, health system preparedness as well as social and economic interventions. ${ }^{20}$ 


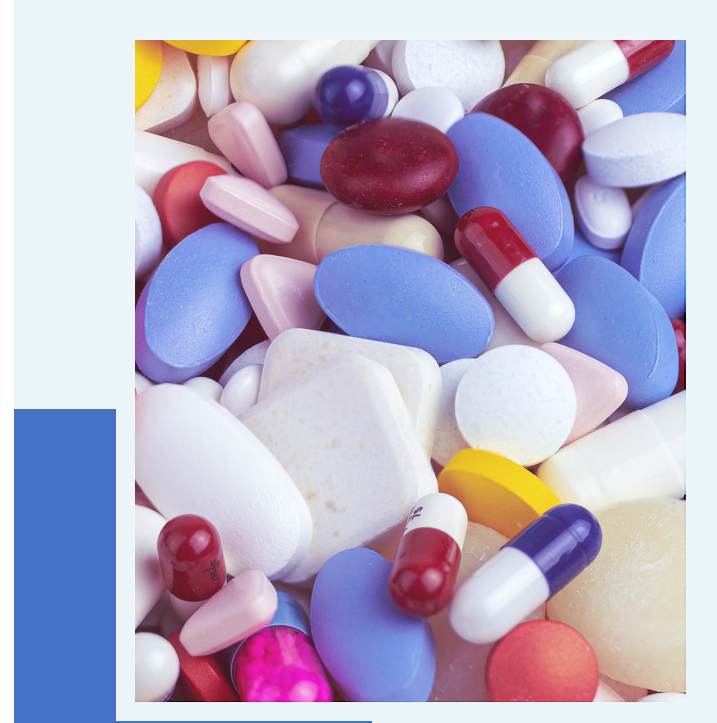

\section{DRIVERS OF GROWTH}

\subsection{DEMOGRAPHIC, EPIDEMIOLOGICAL AND HEALTH TRANSITIONS}

Certain demographic and epidemiological trends are likely to boost the demand for healthcare as well as influence the nature of health services demanded in the years to come.

One such trend is rising income which could result in around 73 Million households moving into the middle-class category in India over the next 10 years, thereby enhancing their purchasing power, including with respect to healthcare. ${ }^{1,2}$ It is expected that $8 \%$ Indians will earn more than USD 12,000 per annum by 2026.,

Another important trend is the increase in life expectancy and ageing. Life expectancy in India is likely to exceed 70 years by 2022 and the country's population is projected to increase to 1.45 Billion by 2028 , making it the most populous nation globally.,2

While on the one hand, India has the largest population of youth compared to any country in the world, on the other, the number of senior citizens $(60+$ years) is also growing. In fact, it is estimated that the share of senior citizens in India's population will double from $8.6 \%$ in 2011 to $16 \%$ by $2041 . .^{9,10}$ In 2050 , India is expected to have 300 Million senior citizens. ${ }^{1}$

Further, India is now faced with a dual burden of disease. While communicable diseases still account for a significant proportion of the disease burden (33\% of Disability Adjusted Life Years [DALYs] lost), a rising morbidity and mortality cost is now attributable to NCDs (55\% of [DALYs] lost)..$^{9,10}$

India currently has around 60 Million diabetics, a number that is expected to swell to 90 Million by $2025 .{ }^{14}$ It is estimated that every fourth individual in India aged above 18 years has hypertension. ${ }^{2,9}$ Nearly 5.8 Million Indians die from NCDs (heart and lung diseases, stroke, cancer and diabetes) every year. ${ }^{10,14}$ The rising NCD burden is estimated to cost India USD 4.58 Trillion before 2030. ${ }^{14}$

Lifestyle disorders are on the rise due to a combination of rising incomes, accelerated pace of urbanisation and increased life expectancy. The fat consumption in diets is increasing, which alongside reduced physical activity, is leading to an upswing in obesity, cardiovascular diseases and cancer. 
An ageing population with a growing middle class and greater longevity will boost the demand for health services in India as well as increasingly favour wellness and preventative services. Additionally, an increase in the prevalence of lifestyle or chronic diseases coupled with higher purchasing capacity will enhance the demand for specialised healthcare. Health insurance coverage is also expected to increase significantly on account of rising income levels and urbanisation.

\subsection{MEDICAL VALUE TRAVEL (MVT)}

MVT is another strong driver of growth for India's healthcare sector. India is fast emerging as an attractive destination for medical value travellers from across the globe. In particular, wellness tourism is growing faster than global tourism, as an increasing number of consumers are incorporating wellness into their travel plans.

\subsection{ENABLING POLICY ENVIRONMENT}

Several recent policy measures will also help to drive the growth of India's healthcare sector. These include increase in public health expenditure to $2.5 \%$ of GDP by 2025 ; implementation of several large-scale and ambitious initiatives like Ayushman Bharat; commitment from the Government to invest USD 200 Billion in medical infrastructure by 2024 as well as the roll out of various schemes under the AatmaNirbhar Bharat Abhiyaan. ${ }^{21}$ The Performance-Linked Incentive (PLI) Scheme and the Scheme for Promotion of Medical Device Parks, in particular, offer significant financial incentives for investors to manufacture in India. A new PLI 2.0 scheme is also being prepared for promotion of the in-vitro diagnostics market.

\subsection{DEMAND-SUPPLY GAP}

In the area of medical diagnostics, India currently has only 2,700 mammograms installed, less than $5 \%$ of the mammograms available in the US.1 Similarly, India has only 120 PET-CT scanners, with most of them concentrated in the metropolitan cities. ${ }^{1}$ Further, only $30 \%$ of cancer centres have advanced imaging technologies.'

With the Government emphasising early diagnosis of NCDs through initiatives like the HWCs, there is an increased demand for medical devices, including for the purpose of large-scale screening. Implementing comprehensive screening programmes as well as targeting specific disease profiles, which are relevant for the indigenous population, and specific communities, can enable early detection of diseases like cancers of the breast, cervix and prostrate.

With respect to the availability of treatment services, similar gaps exist as up to $60 \%$ of health facilities are concentrated in a handful of large cities across the country. ${ }^{1}$ Presently, $30 \%-35 \%$ patients in India undergo surgery compared to 60\%-65\% globally. ${ }^{1}$ Similarly, only $15 \%-20 \%$ of patients in India undergo radiation therapy as against 40\%-50\% globally. ${ }^{1}$ Correcting the skewed spread and density of radiotherapy installations across Government establishments and encouraging the installation of linear accelerators in private institutes, in PPP mode, will help reduce the gap in overall cancer care.

India currently has 1.3 hospital beds per 1,000 population. ${ }^{1,16}$ There is also a shortage of skilled health workers, with 0.65 physicians per 1,000 people (the World Health Organisation standard is 1 per 1,000 people) and 1.3 nurses per 1,000 people.,16

An additional 3 Million beds will be needed for India to achieve the target of 3 beds per 1,000 people by 2025. ${ }^{1}$ Further, another 1.54 Million doctors and 2.4 Million nurses will be required to meet the growing demand for healthcare in India. ${ }^{1.16}$ Demand will also be created on account of 
the expansion of initiatives like Ayushman Bharat (PM-JAY) which will boost requirements for health personnel not only in larger cities but also Tier 2 and Tier 3 cities and villages. India will therefore need to increase the numbers of trained health personnel across various categories to achieve a ratio of at least 2.5 doctors and 5 nurses per 1,000 people by $2034 .^{1,16}$

\subsection{OTHER FACTORS}

Other important drivers of growth for India's healthcare sector will be enhanced adoption of telemedicine and other digital technologies in the post-COVID era as well as the emergence of PPP models in healthcare. Chains of private hospitals are increasingly foraying beyond the metropolitan cities into Tier 2 and Tier 3 cities as well. More and more private players are seeking accreditation and developing new healthcare models. Further, various States have launched innovative initiatives to attract PPP investments into the healthcare space. 


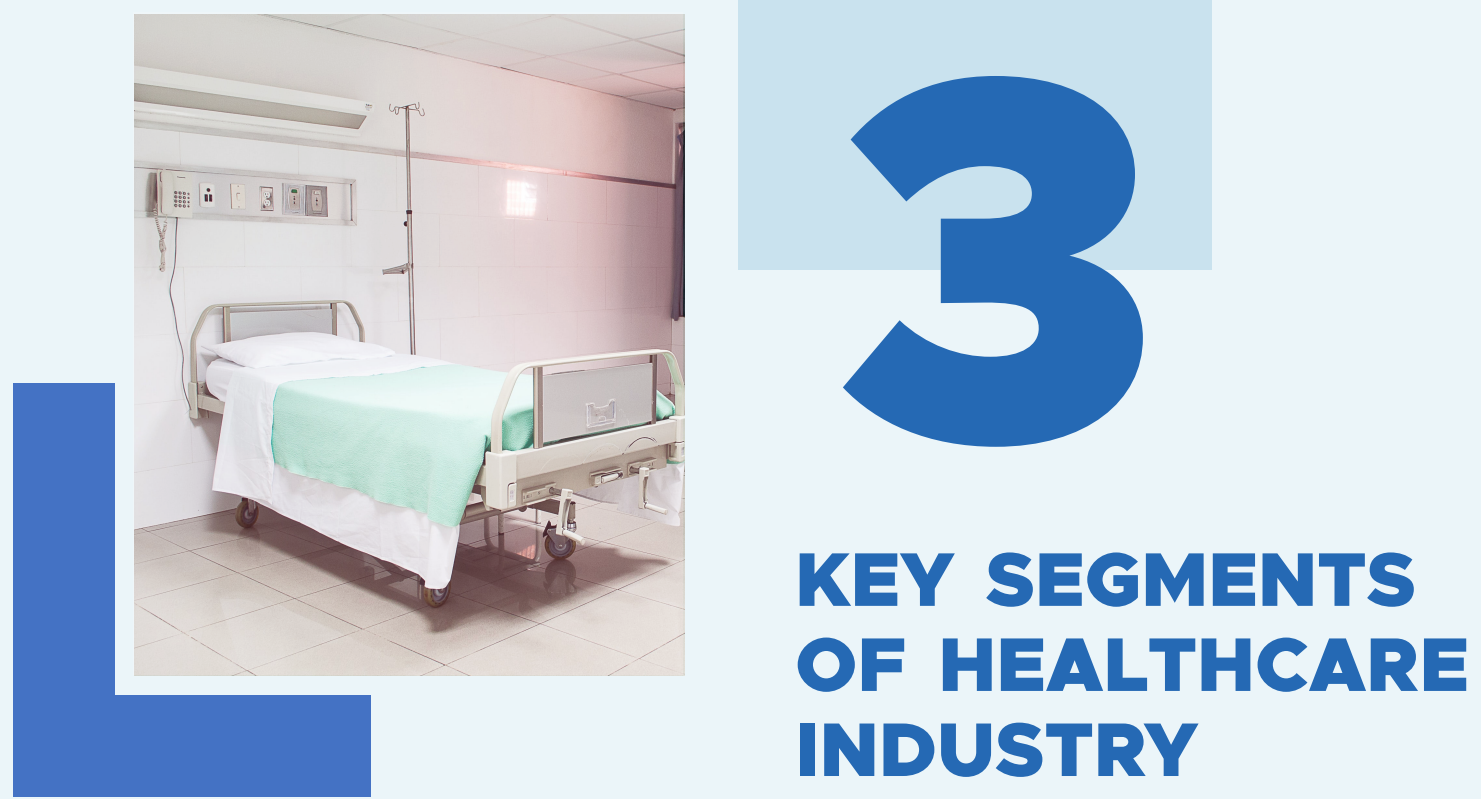

\subsection{HOSPITALS AND INFRASTRUCTURE}

The hospital industry in India accounts for $80 \%$ of the total healthcare market. ${ }^{\text {The }}$ Thng-term outlook for the hospital sector is stable, with annual revenues likely to grow robustly over the next few years on account of rising domestic demand for healthcare as well as medical tourism. It was valued at USD 61.79 Billion in FY17 and is expected to reach USD 132 Billion by 2023, growing at a CAGR of $16 \%-17 \%{ }^{1,16}$

While metropolitan cities like Delhi, Mumbai, Chennai and Kolkata boast of world-class hospital groups (Max, Hinduja, Fortis and Apollo) with high-end infrastructure, healthcare companies are now also expanding into Tier-2 and Tier-3 cities such as Nashik, Indore, Visakhapatnam, Jaipur, Mohali, Surat and Dehradun. These cities offer a unique advantage as the intensity of competition and cost of real estate is considerably lower compared to the metros.

It is noteworthy that around $65 \%$ of hospital beds in India cater to almost $50 \%$ of the population concentrated in Uttar Pradesh, Maharashtra, Karnataka, Tamil Nadu, Telangana, West Bengal and Kerala.,11,16 The other 50\% of the country's population living in the remaining 21 States and 8 Union Territories has access to only 35\% of hospital beds. Simple arithmetic indicates that there is tremendous potential to grow hospitals beds, by at least 30\%, for ensuring equitable access to healthcare for citizens in all parts of the country.

During the nationwide lockdown in India on account of the COVID-19 outbreak, restricted patient movement and fear of infection impacted hospital operations significantly, with planned procedures dropping by as much as $80 \%$ and unplanned procedures reducing by $66 \%$ according to some estimates. The hospital segment, however, began to recover post Unlock-1, with occupancy levels going up to $60 \%$ of pre-COVID times. ${ }^{11}$ It is expected that revenues for this segment will reach pre-COVID levels by Q2 of 2021.,11,16

Non-metros (Tier 2 and 3 cities) are expected to recover faster than the metropolitan areas and Tier 1 cities, as they were less badly hit by the COVID-19 outbreak.11 The same is true for oncology, dialysis, cardiac and neuro-surgeries, which are recovering faster than other segments." Additionally, leading private hospitals may witness growth in the gynaecology and obstetrics segments, in particular, with local hospitals/nursing homes shutting down or becoming non-functional during the Coronavirus outbreak. 


\subsubsection{SPECIFIC ENABLING POLICIES}

The Department of Economic Affairs, Government of India, introduced "the Scheme for Financial Support to PPPs in Infrastructure" in 2006. ${ }^{22}$ The objectives of the scheme are to support economically justified but commercially unviable infrastructure projects, to supplement resources for bridging unmet infrastructure needs and to encourage PPP in infrastructure projects. Under the existing scheme 64 projects have been accorded final approval with a total project cost of INR 34,228 crore and Viability Gap Funding (VGF) of INR 5,639 crore.

A sum of INR 2,100 Crore has been allocated for VGF in social infrastructure projects till 2024-25, split into two sub-schemes. ${ }^{23}$ The first sub-scheme is for a broad array of social sectors including waste water treatment, water supply, solid waste management, health and education. It caters to projects facing bankability issues and insufficient revenue streams for recovering capital costs. The Central Government can provide a maximum of 30\% of capital cost as VGF with the State Government/Sponsoring Central Ministry/Statutory Entity providing an equivalent additional amount (up to $30 \%$ of the capital cost). The second sub-scheme is for demonstration/pilot projects in health and education which may face insufficient revenue streams to recover operational costs fully, in addition to capital costs. The Central Government will provide a maximum of $40 \%$ of the capital cost of such projects. In addition, it could provide a maximum of $25 \%$ of the operational costs of the project during the first five years of commercial operations. The State Government can also provide an equivalent amount: a maximum of $40 \%$ of capital cost and $25 \%$ of operational costs for the first 5 years.

NITI Aayog has proposed a model which enables the upgradation of District Hospitals to medical colleges using the VGF scheme. Under this model, the concessionaire will upgrade the District Hospital as necessary and operate it. It will offer free outpatient treatment, free inpatient treatment for 300 beds as well as for $20 \%$ of the additional beds, and paid treatment in the remaining beds. It will also construct and operate the medical college. This is a unique opportunity to improve medical care in backward or hard-to-reach areas, and simultaneously increase the availability of trained doctors. To facilitate this, NITI Aayog has prepared a set of documents including a Model Concession Agreement (MCA) and a draft Request for Proposals. NITI will provide handholding support to any State Government which in its role as the Sponsoring Authority, identifies District Hospitals suitable for upgradation into medical colleges under this scheme.

\subsubsection{INVESTMENT OPPORTUNITIES}

The hospital industry in India is witnessing huge demand from both global and domestic investors. The Government's plans to increase budgetary allocation for public health spending to $2.5 \%$ of the country's GDP by 2025 , will benefit the hospital sector as well.

There is tremendous demand for tertiary care hospitals and specialty hospitals, in particular. Currently, a considerable gap exists between the number of beds available and the number of beds required. India's hospital bed density is less than half the global average of 3 hospital beds per 1,000 population, implying that an estimated 2.2 Million beds will be required over the next 15 years.111

Apart from metropolitan cities, demand for health services is rising in Tier 2 and Tier 3 locations across the country. The per-capita income in these locations has increased rapidly over the past few years. Further, inputs such as land and labour are available at a lower cost in these cities. An added advantage is that these locations can also cater to the population in nearby villages and towns. 
There are nearly 600 investment opportunities worth USD 32 Billion (INR 2.3 Lakh Crore) in the hospital/medical infrastructure sub-sector on Indian Investment Grid (IIG), a platform maintained by Invest India for showcasing investment opportunities by sector.1,16

Table 4: Investment Opportunities in Hospital/Medical Infrastructure

\begin{tabular}{|l|c|}
\hline \multicolumn{1}{|c|}{ Sector } & Investment Opportunities (IIG) \\
\hline Medical Infrastructure & 582 Opportunities worth USD 32.16 Billion \\
\hline Pharma, Biotech \& Lifesciences & 81 Opportunities worth USD 364.37 Million \\
\hline
\end{tabular}

Stressed assets in the hospital industry can be given preference as brownfield projects to healthcare investors by enabling them to diagnose the challenges. This will ensure a significant reduction in the burden of sick industries in the healthcare sector as well as utilization/ upgradation of existing resources by reducing the expenditure.

\subsection{HEALTH INSURANCE}

Health insurance contributes $20 \%$ to the non-life insurance business, making it the 2nd largest portfolio. According to the India Brand Equity Foundation, the gross direct premium income underwritten by health insurance grew 17.16\% year-on-year to reach INR 516.37 billion (approx. USD 6.87 Billion) in FY20.14 This growth was projected taking into account the rising income levels, increasing awareness in urban areas and growing lifestyle related health demands. Market size of the health insurance sector was calculated by taking into account the number of lives covered and the price per life. The penetration of private health insurance in India is less than $10 \%{ }^{14}$

Over the last several months, there has been surge in claims arising due to the COVID-19 pandemic resulting in a number of insurers entering into strategic partnerships with established companies to offer COVID insurance plans. ${ }^{14} \mathrm{New}$ policies floated cover the cost of PPE kits along with other expenses incurred during COVID treatment.

Multiple stakeholders constitute India's health insurance ecosystem including insurance companies, beneficiaries, provider hospitals, third-party administrators, intermediaries, reinsurers, start-ups, diagnostics, pharmacies, value-added service providers, Government regulators, and Government-funded social insurance schemes.

\subsubsection{SPECIFIC ENABLING POLICIES}

It is envisaged that PM-JAY launched by the Government as part of the Ayushman Bharat initiative could increase the penetration of health insurance in India from $34 \%$ to $50 \% .^{14}$ The COVID-19 pandemic has also created growth opportunities for the insurance market. In June, 2020, the Insurance Regulatory and Development Authority of India (IRDAI), published its guidelines for COVID-19 standard (benefit-based and indemnity) health policies. ${ }^{14}$ Health and general insurance providers have been mandated to offer the indemnity policy. In Union Budget, 2021-22, the Finance Minister announced that the FDI cap for the insurance sector would be increased to $74 \%$ from the current $49 \% .^{13}$ This move should provide a further impetus to the expansion of health insurance in the country.

7 Healthcare. Invest India. https://www.investindia.gov.in/sector/healthcare. 


\subsubsection{INVESTMENT OPPORTUNITIES}

The percentage of the Indian population covered under health insurance has hitherto been relatively insignificant. However, there has been an increase in the number of people opting for health insurance over time. New products that cover certain ailments that were previously not covered are also seeing a heightened demand among buyers of insurance policies.

A growing middle class, coupled with a rising burden of new diseases, is raising the demand for health insurance coverage. Many companies offer health insurance coverage to employees, driving the market penetration of insurance players. With increasing demand for affordable and quality healthcare, penetration of health insurance is poised to grow exponentially in the coming years.

\subsection{PHARMACEUTICALS AND BIOTECHNOLOGY}

The current market size for pharmaceuticals in India is USD 41 Billion which is expected to reach USD 130 Billion by 2030. ' The market size for biosimilars in India is approximately USD 3 Billion and is expected to increase to USD 12 Billion by $2025 .{ }^{1}$ India's biotechnology market is expected to grow at an average growth rate of around 30\% per year to reach USD 100 Billion by $2025.1,14$

India's pharmaceutical sector is the third largest by volume globally. It is also noteworthy that the cost of production in the country's pharmaceutical sector is around 33\% lower than that of the United States and is being continually brought down further. ${ }^{1}$ Quality compliance rates are also high. In fact, India has the highest number (more than 664) of US Food and Drug Administration (US FDA) approved facilities outside the US, over 2,050 World Health Organisation-Good Manufacturing Practices (WHO-GMP) approved pharmaceutical plants and over 697 European GMP compliant plants.,14,16

The major categories within India's pharmaceutical sector include generic drugs, Active Pharmaceutical Ingredients (API)/bulk drugs, over-the-counter drugs, vaccines, contract research and manufacturing as well as biosimilars and biologics. ${ }^{1}$

India has around 60,000 generic brands across 60 therapeutic categories. ${ }^{1}$ The country is the world's largest provider of generic medicines, accounting for $20 \%$ of global generic drugs exports (in terms of volumes). ${ }^{1}$ Currently, 8 out of the top 20 global generic companies are from India. Indian drugs are exported to more than 200 countries in the world, with the US being a key market. ${ }^{1,16}$ As of 2019, India had 98 biosimilars approved in the country, the highest number globally. ${ }^{1,14}$ India also supplies $62 \%$ of the global demand for vaccines. ${ }^{1}$ In fact, India is the number 1 supplier of DPT, BCG, and Measles vaccines. ${ }^{1}$

According to data from the World Trade Organisation, India ranked 3rd globally in terms of volumes of exports and 11th globally with respect to the value of exports in $2019 .{ }^{24,25}$ India is a net exporter of pharmaceutical goods. Between 2016 and 2020, India's pharmaceutical exports grew at a CAGR of 5.98\% and amounted to USD 16.29 Billion in FY20. ${ }^{25}$ During the same period, Indian pharmaceutical imports grew at a CAGR of $9.21 \%$ and amounted to USD 2.3 Billion in FY2O. ${ }^{25}$

Pharmaceutical exports are expected to continue witnessing positive growth. As per a report prepared by EXIM Bank of India, the country's pharmaceutical sector is ripe for the creation of an export hub on account of several factors - the product is among the top 20 export items from India; a globally ranked company is present in India; India is among the top 10 global exporting countries and the global export share of India is rising compared to the last 5 years. ${ }^{26}$ 
Table 5: Imports and Exports in India's Pharmaceutical Sector ${ }^{8}$

\begin{tabular}{|l|l|c|c|c|c|c|}
\hline & & $\mathbf{2 0 1 5 - 2 0 1 6}$ & $\mathbf{2 0 1 6 - 2 0 1 7}$ & $\mathbf{2 0 1 7 - 1 8}$ & $\mathbf{2 0 1 8 - 1 9}$ & $\mathbf{2 0 1 9 - 2 0}$ \\
\hline $\begin{array}{l}\text { Pharmaceutical } \\
\begin{array}{l}\text { Products (USD } \\
\text { Million) }\end{array}\end{array}$ & Exports & 12,910 & 12,930 & 13,255 & 14,754 & 16,289 \\
\hline
\end{tabular}

India's biotechnology industry comprises bio-pharmaceuticals, bio-services, bio-agriculture, bio-industry and bio-informatics. There are more than 2,500 biotechnology companies in India employing approximately 1 Million people. ${ }^{1}$ Around 15,500 biotechnology graduates join the workforce every year. ${ }^{1,16}$

\subsubsection{SPECIFIC ENABLING POLICIES}

Various initiatives have been taken to streamline the clinical trial process and expedite approvals in the pharmaceutical sector. Measures include constituting a committee to facilitate interministerial coordination, integration of portals of different departments into a single online platform for tracking the application status, delegation of reviewing powers to institutional committees as well as enactment of the New Drugs and Clinical Trials Rules, 2019. The latter has greatly streamlined the timelines for seeking approvals. ${ }^{1,14,27}$

As per these Rules, approvals will be granted (else deemed granted) within highly competitive timelines. Additionally, new drugs approved for use in select developed markets will be automatically allowed in India, provided global trials include Indian patients. Safeguard mechanisms have been put in place to ensure that due protocols are adhered to and accountability has been vested with Clinical Trial Sponsors and Investigators for ensuring the same. ${ }^{27}$ Additional steps for promoting India as a clinical trial hub include setting up of animal testing and biocompatibility testing laboratories.

Steps have also been taken by the Government to improve access to medicines. According to the 71st Round of the National Sample Survey Office, $63.5 \%$ of the total Out-Of-Pocket Expenditure (OOPE) on healthcare in India, is dedicated to outpatient care. ${ }^{28}$ Of this, the largest share of expenditure (71\%) is on medicines. ${ }^{28}$ High OOPE is primarily driven by the lack of financial protection for health. Additionally, it can also be attributed to the exorbitant prices levied by pharma companies on non-scheduled drugs.

Over the last few years, the Government has introduced several measures to enable access to essential drugs at affordable prices. The Pradhan Mantri Bhartiya Janaushadhi Pariyojana (PMBJP) is the biggest retail pharmaceutical chain globally. Currently, over 6,600 stores are operational under the scheme across nearly all districts in the country, with around 1 Million cumulative daily customers. ${ }^{16,28}$ The Jan Aushadhi stores presently provide over 1,250 medicines, which the Government aims to expand to 2,000 medicines by the end of March, 2024, thereby covering all major therapeutic groups. ${ }^{16}$ The planned budgetary outlay for the scheme is INR 490 Crore from 2020-25. ${ }^{16,28}$ Citizens can also access free medicines at HWCs under the Ayushman Bharat programme. Similarly, under PM-JAY, drugs are available to patients free of cost at empanelled secondary and tertiary care facilities.

At the given level of financial protection, OOPE on pharmaceuticals can be reduced by emphasising policies which shift consumption away from branded drugs to unbranded generics

8 The Indian pharmaceutical industry - the way forward. Indian Pharmaceutical Alliance. Retrieved December 28, 2020 from https:// www.ipa-india.org/static-files/pdf/publications/position-papers/2019/ipa-way-forward.pdf.

Handbook 2020. Pharmaceuticals Export Promotion Council of India. Ministry of Commerce \& Industry. Government of India. Retrieved January 6, 2021 from https://cdsco.gov.in/opencms/export/sites/CDSCO_WEB/Pdf-documents/NewDrugs_CTRules_2019.pdf. 
which are far more affordable. An important measure going forward would be to address the challenges faced by the Jan Aushadhi stores, including ensuring the viability of private stores, improving procurement and supply chain processes, enhancing the levels of public awareness, as well as encouraging doctors to recommend generic drugs sold at these stores. In addition, utilization of budgets allocated for drugs under the National Health Mission can be further improved.

Specifically, for strengthening the pharmaceutical industry, the Government is investing heavily in building a skilled talent pool through initiatives like the National Institutes of Pharmaceutical Education \& Research (NIPERS), which are hubs of innovation and advanced research. ${ }^{25}$ In 2018-19, India produced over 246,000 pharmacy graduates and over 8.8 Million graduates in science, technology, and engineering..$^{24,25}$

As part of the overarching vision to make India 'aatmanirbhar' (self-reliant), a number of steps have been taken by Government to promote investment in the health sector. ${ }^{21} \mathrm{PLI}$ schemes have been announced for Key Starting Materials (KSMs), Drug Intermediaries (DIs) and APIs to boost domestic manufacturing of 53 bulk drugs. The total financial outlay under the scheme is INR 6,940 Crore. In addition, a Productivity Linked Scheme for promoting the domestic manufacturing capacity of the pharmaceutical industry as well as enhancing exports of pharma products, including biopharmaceuticals, orphan drugs, cell-based and gene therapy products, APIs, KSMs, DIs, anti-infective drugs, anti-diabetic drugs and cardiovascular drugs, will be implemented at a total cost of INR 15,000 Crore.

Further, a scheme for promotion of bulk drug parks to the tune of INR 3,000 Crore has been developed to reduce the manufacturing cost of bulk drugs in the country. Similarly, a scheme for the promotion of medical device parks with a total financial outlay of INR 400 Crore has been announced to reduce the cost of indigenous manufacturing. The "Ind-CEPI" mission, and, more recently, the COVID Suraksha Mission (financial outlay INR 900 Crore), have also been launched to boost the development and testing of indigenous vaccine candidates.

Table 6: Schemes in the AatmaNirbhar Bharat Abhiyaan Package for Boosting Domestic Manufacturing of Drugs ${ }^{9}$

\begin{tabular}{|c|c|}
\hline \multicolumn{2}{|c|}{$\begin{array}{l}\text { Production Linked Incentive (PLI) Scheme for promotion of domestic manufacturing of critical } \\
\text { KSMs/Drug Intermediates \& APIs }\end{array}$} \\
\hline Overview & $\begin{array}{l}\text { A financial incentive will be given to eligible manufacturers of identified } 41 \\
\text { products on incremental sales over base year FY2019-2020 for } 6 \text { years. }\end{array}$ \\
\hline Incentive & $\begin{array}{l}\text { Fermentation based drugs - } 20 \% \text { (of incremental sales value) } \\
\text { Chemical Synthesis based drugs - 10\% (of incremental sales value) }\end{array}$ \\
\hline Total Financial Outlay & INR 6,940 Crore (USD 938 Million) \\
\hline Tenure & FY2O2O-2O21 to FY2O29-2030 \\
\hline \multicolumn{2}{|c|}{ Scheme for Promotion of Bulk Drug Parks } \\
\hline Overview & $\begin{array}{l}\text { One-time grant-in-aid will be given to States for the development of } 3 \\
\text { Bulk Drug Parks with common infrastructure facilities, including solvent } \\
\text { storage systems, logistics, testing, and effluent treatment plant facilities. }\end{array}$ \\
\hline Incentive & INR 1,000 Crore (USD 135 Mn)/bulk drug park \\
\hline Total Financial Outlay & INR 3,000 (USD 405 Million) \\
\hline Tenure & FY2O2O-2O21 to FY2O24-2025 \\
\hline
\end{tabular}

9 AatmaNirbhar Bharat Abhiyan. Government of India. Retrieved January 15, 2021 from https://aatmanirbharbharat.mygov.in/. 
PLI Scheme for promotion of domestic manufacturing of Pharmaceutical Products (New PLI released in November, 2020)

\begin{tabular}{|l|l|}
\hline Overview & $\begin{array}{l}\text { India possesses a complete ecosystem for the development and } \\
\text { manufacturing of pharmaceuticals and a robust ecosystem of allied } \\
\text { industries. The new PLI scheme will incentivize global and domestic } \\
\text { players to engage in high-value production. }\end{array}$ \\
\hline Category 1 \\
Products \\
i. Biopharmaceuticals ii. Complex generic drugs iii. Patented drugs or \\
Orughearing patent expiry iv. Cell-based or gene therapy products v. \\
Orphan drugs vi. Special empty capsules vii. Complex excipients \\
Category 2 \\
i. APIs/KSMs and/DIs \\
Category 3 \\
i. Repurposed drugs ii. Auto-immune drugs, anti-cancer drugs, antidiabetic \\
drugs, anti-infective drugs, cardiovascular drugs, psychotropic drugs, \\
and anti-retroviral drugs iii. In-vitro Diagnostic Devices (IVDs) iv. \\
$\begin{array}{l}\text { Phytopharmaceuticals v. Other drugs not manufactured in India vi. Other } \\
\text { drugs as approved }\end{array}$
\end{tabular}

For strengthening the biotechnology sector, the Government is implementing various initiatives $^{29}$ like the Biotechnology Industry Research Assistance Council (BIRAC), Bio-NEST and BioTech Science Clusters.

BIRAC is a not-for-profit Section 8, Schedule B, Public Sector Enterprise, set up by Department of Biotechnology (DBT), Government of India as an interface agency to strengthen and empower the emerging biotech enterprise to undertake strategic research and innovation, addressing nationally relevant product development needs. BIRAC is an industry-academia interface and implements its mandate through a wide range of impact initiatives, be it providing access to risk capital through targeted funding, technology transfer and handholding schemes that help bring innovation excellence to biotechnology firms. BIRAC has initiated several schemes, networks and platforms that help to bridge the existing gaps in industry-academia Innovation research and facilitate novel, high quality affordable products development through cutting edge technologies. The development of India's first indigenously developed DNA vaccine candidate against COVID-19, ZyCoV-D, was supported by the National Biopharma Mission under the aegis of BIRAC and the DBT.

Bio-NEST provides incubation space to start-ups and entrepreneurs; connects industry and academia and enables interactions for efficient exchange of knowledge, technical and business mentorship. It also provides enabling services and the required mentorship for intellectual property and technology management as well as resource mobilization.

To promote entrepreneurship, the National Biotechnology Development Strategy aims to establish India as a world-class bio-manufacturing hub by creating a technology development and translation network across the country through the establishment of bio-clusters, incubators and technology transfer centres. Four bio-clusters have been established at Faridabad, Bangalore, Kalyani and Pune for catalysing research and development and entrepreneurship activities. Additionally, the Department of Biotechnology, Ministry of Science and Technology, Government of India is inviting proposals for establishing the Biotech URJIT Clusters. These Clusters will be set up by synergising resources between institutions, university research laboratories and industry, including small and medium sized enterprises, for technology and product development as well as enterprise building. 


\subsubsection{INVESTMENT OPPORTUNITIES}

Over 500 types of APIs are manufactured in India. ${ }^{1}$ The country contributes $57 \%$ of APIs to the WHO's prequalified list. ${ }^{1}$ In FY20, 33\% of all Abbreviated New Drug Applications were filed by Indian companies. ${ }^{1,24}$

Hitherto, India has been heavily dependent on China for APIs. In fact, up to $80 \%$ of India's API imports are sourced from China. ${ }^{1}$ The recently announced PLI schemes of the Government can help reduce this dependence on China and boost domestic manufacturing significantly. Moreover, between 2018 and 2024, patents worth USD 251 Billion are going to expire globally, which will also present a lucrative opportunity for the Indian pharmaceutical sector.

In addition to generic drugs, there are several investment opportunities in other segments of India's pharmaceutical sector as well including over-the-counter drugs, vaccines and contract manufacturing and research. The cultural popularity of Ayurvedic therapies is contributing to high sales of related over-the-counter formulations. Growth in demand is driven by the increased purchasing power of the middle class as well as greater awareness. Additionally, over-the-counter products have been included in the Jan Aushadhi outlets.

India supplies 1.5 Billion doses of vaccines every year, with exports to the tune of USD 410 Million across over 150 countries. ${ }^{1,24}$ In fact, 70\% of WHO's vaccine requirement (as per the essential immunization schedule) is sourced from India. ${ }^{1}$

India is also a preferred destination for clinical trials due to a heterogeneous patient pool, cost competitiveness, a skilled labour pool, as well as rising costs in developed markets. Cost of clinical trials in India is 40\%-60\% lower than developed markets. ${ }^{27}$ India has over 500 contract research labs and over 600,000 English-speaking, skilled investigators., ${ }^{1,27}$

\subsection{MEDICAL DEVICES, EQUIPMENT AND DIAGNOSTICS}

Medical devices represent a sunrise sector of the Indian economy. With relatively lower barriers to entry compared to other industries, the size of the Indian medical devices market is estimated at USD 11 Billion, expected to grow to USD 50 Billion by 2025. ${ }^{1}$ The medical devices sector has been growing steadily at a CAGR of 15\% over the last 3 years. ${ }^{1}$ India's diagnostics market is currently valued at USD 4 Billion. ${ }^{1}$ The share of the organised sector in this segment is almost $25 \%$ ( $15 \%$ in labs and $10 \%$ in radiology). 1 The diagnostics market expected to grow at a CAGR of $20.4 \%$ to reach USD 32 Billion by 2022. ${ }^{1,30}$ Further, export of medical devices by India is expected to reach USD 10 Billion by $2025{ }^{1}$

Currently, India is the 4th largest medical devices market in Asia, after Japan, China, and South Korea. ${ }^{1}$ It is also among the top 20 markets globally. ${ }^{1}$ There are over 6,000 types of medical devices in India., ${ }^{1,30}$ Presently, it is estimated that India imports nearly $86 \%$ of its medical devices. ${ }^{1}$ In particular, the country is dependent on imports for higher-end medical products such as cancer diagnostics, medical imaging tools, ultrasonic scans and PCR technologies.

India's trade in medical devices has increased though India remains a net importer. In 2019-20, India's medical devices imports stood at USD 1.77 Billion against exports of USD 0.99 Billion.1,16 However, in recent years, the CAGR of exports (10.22\%) scores over the import CAGR (5.89\%), indicating the growing export potential of the sector..$^{14,16}$

The medical devices sector has also seen a significant flow of investments over the last few years, with the Government allowing 100\% Foreign FDI under the automatic route. ${ }^{1}$ 
Table 7: Imports and Exports in India's Medical Devices Sectorio

\begin{tabular}{|c|c|c|c|c|c|c|}
\hline & & $2015-2016$ & $2016-2017$ & $2017-18$ & $2018-19$ & $2019-20$ \\
\hline $\begin{array}{c}\text { Medical Devices } \\
\text { (USD Million) }\end{array}$ & Exports & 606 & 621 & 683 & 823 & 986 \\
\hline & Imports & 1,326 & 1,351 & 1,525 & 1,765 & 1,766 \\
\hline
\end{tabular}

Four classes (A, B, C and D) of medical devices are manufactured in India as per the Global Harmonization Task Force Rules. ${ }^{1}$ The manufacturing value chain for the high-end medical devices ( $C$ and $D$ ) is led by multinational companies that have extensive service networks in India. This segment has over 90\% dependency on imports and therefore also provides considerable opportunities for investment to devise a focused approach for minimizing the trade deficit. ${ }^{30}$ Classes $A$ and $B$, on the other hand, which are relatively less technologically advanced, are produced largely by domestic manufacturers. Most of the Indian manufacturers of these devices are Micro, Small \& Medium Enterprises (MSMEs) with an average turnover of USD 450-500 Million. ${ }^{30}$
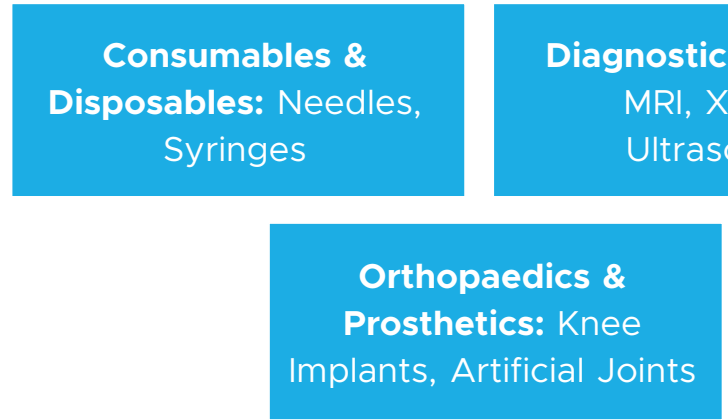
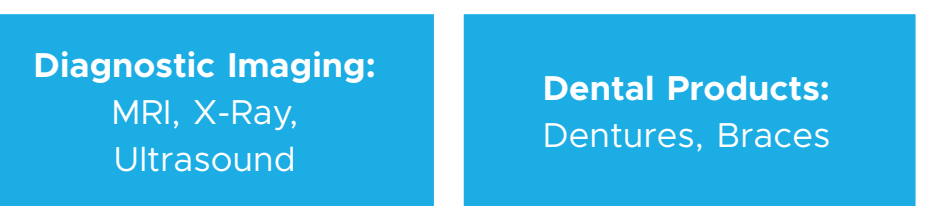

Patient Aids: Hearing

Aids, Pacemakers

Figure 4: Key Segments under Medical Devices"11

The start-up ecosystem in India's medical devices sector is diverse and vibrant, with over 250 organisations engaged in innovations for addressing important health issues. ${ }^{1}$ For instance, Consure Medical is an organisation that is developing devices to provide therapy for tackling faecal incontinence. BeatO has designed a convenient and smart device for measuring blood sugar levels. Forus Health is a medical technology start-up that has designed and developed affordable technology solutions for increasing access to eye care. Other promising examples include Indiolabs, a company developing platform technology devices for soft tissue core biopsy, as well as Sattva MedTech, a leading Indian medical start-up, working in the area of child and maternal healthcare.

A challenge for the medical devices industry is the cost of manufacturing disability of around $12 \%-15 \%$, vis-a-vis competing economies, primarily on account of lack of adequate infrastructure, inadequate domestic supply chain and logistics, high cost of finance and power, shortage of quality power, limited design capabilities as well as inadequate focus on research \& development.1,16,30

The COVID-19 pandemic also impacted the medical devices sector, with sales of many devices dropping to 20\% in April 2020 as compared to the sales in April 2019. ${ }^{30} \mathrm{It}$ is, however, envisaged that India's medical technology sector will reach pre-COVID levels by Q4 of $2021 .^{30}$

10 Healthcare. India Brand Equity Foundation. Retrieved December 15, 2020 from https://www.ibef.org/download/Healthcare-July-2019. pdf.

Healthcare. Invest India. https://www.investindia.gov.in/sector/healthcare.

11 Healthcare. Invest India. https://www.investindia.gov.in/sector/healthcare. 


\subsubsection{SPECIFIC ENABLING POLICIES}

The Jan Aushadhi stores presently provide over 204 types of surgical equipment, which the Government aims to expand to 300 surgical products by the end of March $2024.14,^{16}$ Citizens can also access free diagnostics at HWCs under the Ayushman Bharat programme. Similarly, under PM-JAY, medical devices are available to patients free of cost at empanelled secondary and tertiary care facilities.

Recognising the critical role played by medical devices in ensuring a well-functioning healthcare system, the Ministry of Health \& Family Welfare (MoHFW) notified the Medical Devices Rules, 2017. ${ }^{14,16,28}$ Previously, only 15 categories of devices were subject to regulation, that too under the umbrella of drugs. The Rules, on the other hand, acknowledge the increasing diversity of devices and have been framed in alignment with international best practices. As per the Rules, devices have been classified and will be regulated according to their risk profile. For ensuring that devices adhere to the highest quality standards, the Rules emphasise third-party evaluation and certification. The process of applying for a manufacturing license has also been streamlined through an online electronic platform. In order to improve the availability of quality diagnostics across health facilities in India, the National Essential Diagnostics List has also been finalised.

In order to boost indigenous manufacturing of medical devices, the Government has adopted a 'Manufacturing Ecosystem Cluster Development' approach.,16,28 Medical device parks are being developed around five device manufacturing clusters in the country. State Governments are committed to setting up dedicated industrial parks for enabling efficient domestic manufacturing at lower costs. These parks will provide all the essential infrastructure, allowing companies to 'plug and play'. As a consequence, industry estimates suggest that the cost of production will be reduced by $40 \%-50 \%$. Further, companies will have easy access to in-house standard manufacturing/testing facilities as well as consolidated raw material procurement. They will be able to use the common facilities and pay for them on a per-unit manufactured basis. Crucially, this mechanism will ensure that all necessary approvals are in place before hand, thereby reducing the time taken to begin commercial production.

In 2019, Andhra Pradesh, Telangana, Tamil Nadu and Kerala were accorded in-principal approval for establishing new medical devices parks. The Andhra Pradesh MedTech Zone (AMTZ) is a comprehensive healthcare ecosystem for providing capital intensive scientific facilities required by most medical devices manufacturers and over 200 modern independent manufacturing units. ${ }^{31}$ AMTZ has nurtured institutions like the Kalam Institute of Health Technology, Indian Biomedical Skill Consortium, Medivalley and Biovally Incubation Council, which provide support for policy initiatives as well as consultancy on various healthcare projects in the country.

AMTZ is also focusing on critical components research. Critical components contribute only $20 \%$ of medical devices manufacturing but strategically block the indigenization or improvisation of domestic medtech. These components are not manufactured in India and importing them makes medtech commercially unviable. As a result, India has been importing finished medtech products for several decades at a huge cost to the exchequer. It is therefore important to address this chronic manufacturing disability. Moreover, apart from robust domestic demand there is strong global potential for these components due to the presence of a relatively small number of manufacturers in the global markets. During the COVID-19 pandemic, AMTZ produced over 15,000 ventilators, 10 Million COVID diagnostic kits, 500,000 N-95 masks and 200,000 Personal Protective Equipment kits.

As per the Competitive Public Procurement Order, the Government is also giving preference to local suppliers of medical devices and equipment during tender selection. ${ }^{16}$ 
Under the AatmaNirbhar Bharat Abhiyaan, a PLI scheme for manufacturing of medical devices in four identified categories has also been announced with a total financial outlay of INR 3,420 Crore. ${ }^{21}$ Multiple efforts are being made to strengthen the research and development ecosystem in the country for innovation of new technologies in medical devices as well as product optimization of existing technologies. The scheme for development of MedTech Zones with common scientific and manufacturing facilities is also part of the AatmaNirbhar Bharat package.

Table 7: Schemes in the AatmaNirbhar Bharat Package for Boosting Domestic Manufacturing of Medical Devices ${ }^{12}$

\begin{tabular}{|c|c|}
\hline \multicolumn{2}{|c|}{$\begin{array}{l}\text { Production Linked Incentive (PLI) Scheme for promotion of domestic manufacturing of } \\
\text { medical devices }\end{array}$} \\
\hline Overview & INR 3,420 Crore \\
\hline Incentive & $\begin{array}{l}5 \% \text { of incremental sales over base year } 2019-20 \text { will be provided on } \\
\text { the segments of medical devices identified under the scheme. }\end{array}$ \\
\hline Total financial outlay & INR 121 Crore \\
\hline Tenure & FY $2020-2021$ to FY 2027-2028 \\
\hline \multicolumn{2}{|r|}{ Promotion of Medical Devices Parks } \\
\hline Overview & $\begin{array}{l}\text { A one-time grant-in-aid will be provided for creation of common } \\
\text { infrastructure facilities in selected medical device parks proposed by } \\
\text { a State Government }\end{array}$ \\
\hline Incentive & 100 Crore per park \\
\hline Total financial outlay & INR 400 Crore \\
\hline Tenure & FY $2020-2021$ to FY 2024-2025 \\
\hline
\end{tabular}

\subsubsection{INVESTMENT OPPORTUNITIES}

The Government recently introduced a cess of $5 \%$ on import of certain medical goods to help finance healthcare infrastructure and services. ${ }^{1.14}$ This increases the cost of importing medical devices in India thereby supporting domestic manufacturers.

There are significant growth opportunities in India's diagnostics sector. Over the next few years, growth is expected to continue at a fast pace. Diagnostic and pathology centres are also expanding their offering to include various kinds of services in specialised areas like cardiology and neurology. A challenge for the sector currently is that it is highly fragmented, divided between organised labs, standalone and hospital-based centres. Large investors are, however, building hub-and-spoke structures, thereby consolidating the industry. The notification of the Clinical Establishment (Central Government) Rules, 2019, will also lead to standardisation and better quality. ${ }^{1,14,16}$

Another area of growth is miniaturised diagnostics as it is now becoming possible to diagnose many conditions very cheaply with a small hand-held device or an add-on to a smartphone. The capability of such devices is increasing exponentially as is their potential to diagnose a large number of ailments instantly at a low cost.

12 AatmaNirbhar Bharat Abhiyan. Government of India. Retrieved January 15, 2021 from https://aatmanirbharbharat.mygov.in/. 


\subsection{MEDICAL VALUE TRAVEL}

MVT or medical tourism is a growing sector in India. In mid-2020, India's medical tourism sector was estimated to be worth USD 5-6 Billion. ${ }^{1.16}$ The valuation was expected to be in the range of USD 9 Billion by 2020, prior to the COVID-19 outbreak..$^{14,16}$ The segment is expected to grow to USD 13 Billion by 2022. ${ }^{1.14}$ In 2017, India ranked 7th in the top 20 wellness tourism markets globally and $3 r d$ in the top 10 wellness tourism markets in Asia-Pacific.116

Several factors make India a popular medical tourism destination. These include presence of world-class hospitals and skilled medical professionals; superior quality healthcare; low treatment costs in comparison with other countries ${ }^{32}$; credibility in alternative systems of medicine as well as increased global demand for wellness services like Yoga and meditation.

India has around 37 Joint Commission International $(\mathrm{JCl})$ accredited hospitals as well as 513 National Accreditation Board for Hospitals \& Healthcare Providers (NABH) accredited hospitals.114 Clinical outcomes in leading hospitals in India are comparable to those of internationally recognised facilities.

Table 8: Prices of Common Medical Procedures Across Major Destinations for Medical Value Travel (USD) ${ }^{13}$

\begin{tabular}{|l|l|l|l|l|l|l|}
\hline Medical Procedure & India & Thailand & Malaysia & Singapore & Turkey & South Korea \\
\hline Heart Bypass & 7,900 & 15,000 & 12,100 & 17,200 & 13,900 & 26,000 \\
\hline Angioplasty & 5,700 & 4,200 & 8,000 & 13,400 & 4,800 & 17,700 \\
\hline Heart Valve Replacement & 9,500 & 17,200 & 13,500 & 16,900 & 17,200 & 39,990 \\
\hline Hip Replacement & 7,200 & 17,000 & 8,000 & 13,900 & 13,900 & 21,000 \\
\hline Hip Resurfacing & 9,700 & 13,500 & 12,500 & 16,350 & 10,100 & 19,500 \\
\hline Knee Replacement & 6,600 & 14,000 & 7,700 & 16,000 & 10,400 & 17,500 \\
\hline Spinal Fusion & 10,300 & 9,500 & 6,000 & 12,800 & 16,800 & 16,900 \\
\hline Dental Implant & 900 & 1,720 & 1,500 & 2,700 & 1,100 & 1,350 \\
\hline Lap Band & 7,300 & 11,500 & 8,150 & 9,200 & 8,600 & 10,200 \\
\hline Gastric Sleeve & 6,000 & 9,900 & 8,400 & 11,500 & 12,900 & 9,950 \\
\hline Gastric Bypass & 7,000 & 16,800 & 9,900 & 13,700 & 13,800 & 10,900 \\
\hline Hysterectomy & 3,200 & 3,650 & 4,200 & 10,400 & 7,000 & 10,400 \\
\hline Breast Implant & 3,000 & 3,500 & 3,800 & 8,400 & 4,500 & 3,800 \\
\hline Rhinoplasty & 2,400 & 3,300 & 2,200 & 2,200 & 3,100 & 3,980 \\
\hline Rhytidectomy & 3,500 & 3,950 & 3,550 & 440 & 6,700 & 6,000 \\
\hline Liposuction & 2,800 & 2,500 & 2,500 & 2,900 & 3,000 & 2,900 \\
\hline Abdominoplasty & 3,500 & 5,300 & 3,900 & 4,650 & 4,000 & 5,000 \\
\hline Lasik (Both Eyes) & 1,000 & 2,310 & 3,450 & 3,800 & 1,700 & 1,700 \\
\hline IVF Treatment & 2,500 & 4,100 & 6,900 & 14,900 & 5,200 & 7,900 \\
\hline & & & & &
\end{tabular}

\section{Low Price}

Moderate Price

High Price

The number of Foreign Tourist Arrivals (FTAs) in India on medical visa grew to an estimated 697,000 in 2019 from 495,056 in 2017.33 India's medical visitors have historically come primarily from Afghanistan, Pakistan, Oman, Bangladesh, Maldives, Nigeria, Kenya and Iraq.

13 India: Building Best Practices in Healthcare Services Globally. FICCI. Retrieved January 5, 2021 from http://ficci.in/spdocument/23136/ FICCl-EY-Report-on-MVT.pdf. 
Popular specialities for MVT in India include cardiac care, orthopaedics, organ transplantation, neurosciences, oncology and bariatrics.

Increasingly, the focus on strong branding of alternative medicine and rejuvenation therapies, along with an emphasis on wellness and prevention, is drawing patients to India from across the globe. Wellness tourism that builds on India's strengths in Ayurveda and Yoga, in particular, is a fast-emerging and growing segment within India's MVT sector. Several major players like Apollo and the Manipal Group are setting up wellness centres, with traditional healthcare remedies as a key focus of their offerings. Many hotels/resorts in the country, especially in the southern States, are establishing Ayurveda Centres. Leading tour operators have also included Ayurveda in their brochures.

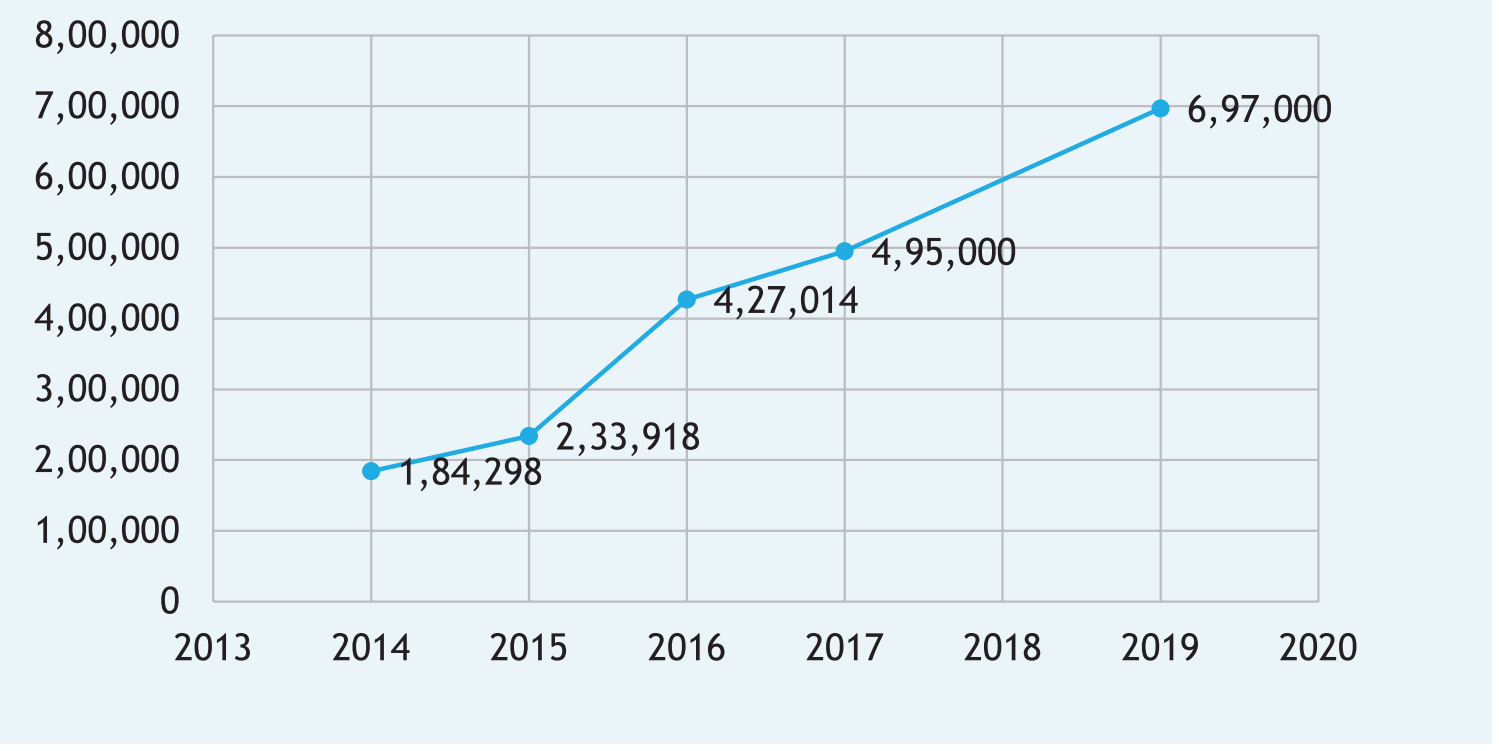

Figure 5: Number of Foreign Tourist Arrivals in India on Medical Visa ${ }^{14}$

\subsubsection{SPECIFIC ENABLING POLICIES}

In 2018, the Government established a dedicated fund of INR 5,000 Crore for enhancing 12 "Champion Services Sectors", MVT being one of them. ${ }^{28}$ The e-tourist visa launched in September, 2014 for easing the visa regime was subsequently expanded to include medical visits as well. ${ }^{28}$ The provision of an e-tourist visa for medical attendants has also been introduced. Further, the medical visa process has been simplified to allow multiple entries and long-term stay.

The Government has also been implementing various initiatives to promote Ayurveda, Yoga and other Indian Systems of Medicine in the international arena. An allocation of INR 2,970 Crore has been made for the Ministry of AYUSH in the Union Budget 2021-22, compared to a sum of INR 2,122 Crore allocated for the Ministry in the 2020-21 Budget. ${ }^{13}$ Guidelines $^{2}$ for accreditation of Ayurveda and Panchkarma Centres have been circulated to all State Governments for implementation.1,32 With an increased focus on the potential of AYUSHrelated therapies for chronic diseases, including mental health, India is becoming a destination for many international travellers.

14 India Tourism Statistics 2019. Ministry of Tourism. Government of India. Retrieved January 2, 2021 from https://tourism.gov.in/sites/ default/files/2020-04/India\%20Tourism\%20Statistics\%202019.pdf. 


\subsubsection{INVESTMENT OPPORTUNITIES}

While MVT has been adversely affected by COVID-19, it is expected to recover over the next few months and continue to grow rapidly thereafter. The number of $\mathrm{JCl}$ accredited hospitals in India is substantial and growing, however, there is a need to further upgrade standards to bring service levels on a par with global standards. This demand has created excellent opportunities for investors. Most healthcare players have been setting up additional facilities to cater to critical care or provide super-specialty services. Several leading hospital players are also aggressively raising funds for their expansion. Growth of the medical tourism segment is additionally creating investment opportunities in advanced diagnostic equipment as well as institutions for training professionals, both nursing and paramedical.

Wellness tourism is an especially high-potential area of growth for India in the post-COVID era given its strengths in alternative systems of medicine. India offers a unique value proposition to the world in this regard. We can deliver an outstanding experience and truly invite the world to 'Heal in India'. Creation of healthcare zones comprising hospitals, hotels, leisure and fitness activities, is another area of opportunity.

\subsection{HOME HEALTHCARE}

Home healthcare is unique not only because care is provided at home, but is also usually less expensive, more convenient, and can be just as effective as the care given in a hospital or skilled nursing facility. Home healthcare saves on real estate and infrastructure as the model effectively operates at 15\%-30\% reduced costs in comparison to hospital expenses for similar treatment. $^{8}$ It is estimated that home healthcare has the potential to replace up to $65 \%$ of unnecessary hospital visits in India and reduce hospital costs by $20 \% .^{8}$ In 2020 , the Indian home healthcare market was valued at approximately USD 6.2 Billion. ${ }^{1,16}$ It is expected to grow at a CAGR of $19.2 \%$ and reach USD 21.3 Billion by 2027.116

The home healthcare market can be categorised broadly into 3 segments:

- Home healthcare services: at-home nursing services, medical consultations

- Home healthcare devices: health screening, monitoring, and self-diagnostic devices like pulse oximeters

- Home healthcare solutions: telehealth and telemedicine

Post-operative care is an important part of the home healthcare segment. Many large hospitals are now offering it with extensive continuum of care. Technology-enabled healthcare companies offer sophisticated critical care at home, including advanced facilities like respiratory services (home ventilation), sleep apnoea care, palliative care, cancer support services, post trauma/ accident care and specialised rehabilitation services (such as pulmonary, neuro, and cardiac rehabilitation; speech therapy). Additionally, end-of-life services are on offer for terminally ill patients as well as personalised care plans formulated in conjunction with doctors.

The home healthcare process includes elements like in-depth clinical evaluation of the patient, systematic clinical audits, availability of highly qualified and expert ICU caregivers, equipment augmented by futuristic tech-based apps, remote monitoring of patients and round-the-clock supervision of patient health by ICU doctors. Even the previously unthinkable advanced care such as haemodialysis and chemotherapy are now making their way into the home healthcare arena.

Adoption of home healthcare solutions in India is currently at a relatively nascent stage. However, it is a sunrise sector with tremendous potential for growth in the years to come on account 
of a rising elderly population, increase in the incidence of chronic diseases necessitating longterm care, enhanced demand for constant personalised care, which is typically unavailable in formal hospital settings, as well as increasingly nuclear family structures in urban areas. ${ }^{34}$ Currently, the service tax department does not consider treatment provided to senior citizens under the definition of healthcare services. ${ }^{35}$ Going forward, it will be important to consider medical services provided to the elderly at home as healthcare services and apply Goods and Services Tax (GST) exemption on them. This will benefit senior citizens who constitute about $12 \%$ of the population and require care at home..$^{35}$

\subsubsection{INVESTMENT OPPORTUNITIES}

The Coronavirus pandemic is likely to provide an impetus to the expansion of the home healthcare market in India. 34,35 With social distancing as the new norm and hospital visits becoming riskier; telemedicine solutions are fast emerging as a convenient alternative. In 2020, many hospitals, individuals, corporates, and e-pharmacies in India adopted telehealth. A convenient way to evaluate and treat a patient without being exposed to infection, the telemedicine segment is expected to significantly rise in the market post the lockdown period as well.

During the initial phase of the lockdown, the market for nursing services saw a considerable decline. However, with outdoor medical capacities crossing their threshold and the Government taking initiatives to train and employ home care nurses, the market is expected to grow rapidly.

Similarly, with travel restrictions and the risk of contagion upon stepping outside the home, there has been a significant escalation in the demand for at-home health screening and monitoring devices.

IRDAI, under its guidelines released in 2020, included homestay and care for COVID-19 under the standard health policy. ${ }^{14}$ As per the guidelines, the insurer has to cover the cost of COVID treatment incurred by the insured person on availing treatment at home for a maximum period of 14 days. This move is expected to have a major impact on home healthcare markets now and in the future.

\subsection{TELEMEDICINE AND OTHER TECHNOLOGY-RELATED HEALTH SERVICES}

The market size for telemedicine in India was around USD 830 Million in 2019. It is projected to increase to USD 5.5 Billion by 2025 growing at a CAGR of 31\% during 2020-25. ${ }^{36}$ 


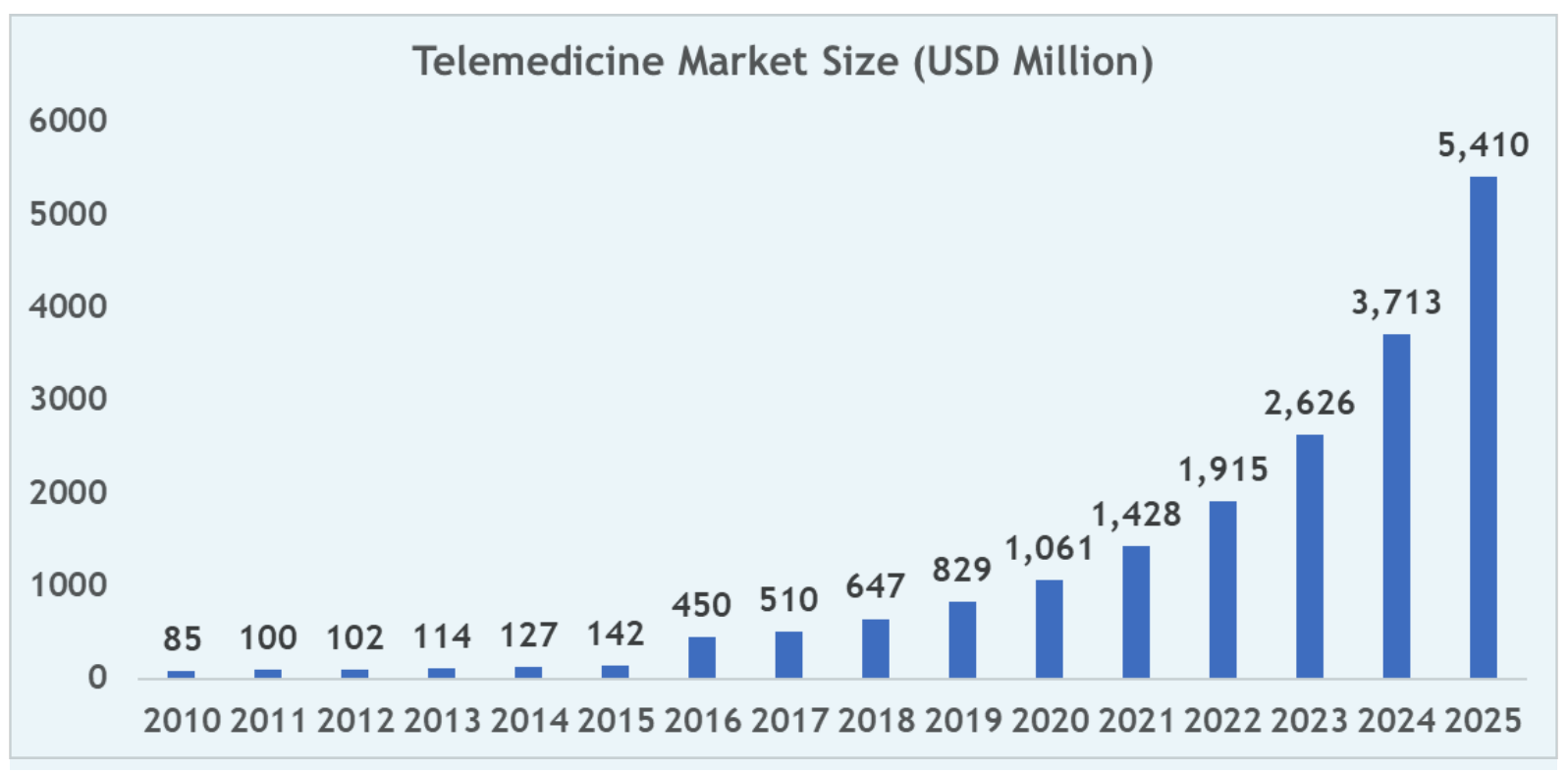

Figure 6: India's Telemedicine Market Size 2010-2019, with estimates till 202515

\subsubsection{SPECIFIC ENABLING POLICIES}

The Telemedicine Practice Guidelines were released jointly by MoHFW and NITI Aayog in March 2020 to ensure that access to medical advice does not become challenging due to social distancing norms enforced following the COVID-19 outbreak.37 The Guidelines, coupled with the Government's tele-consultation services, e-Sanjeevani and e-Sanjeevani OPD, have leveraged information communication technologies to enable diagnosis, treatment and management of diseases. By early December 2020, over 1 Million tele-consultations had taken place through e-Sanjeevani across 550 districts in India.38 Inclusion of telemedicine in the NDHM's digital suite will further help connect patients with doctors and specialists.

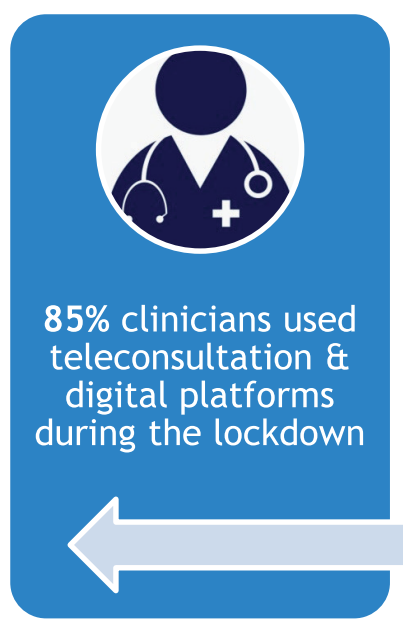

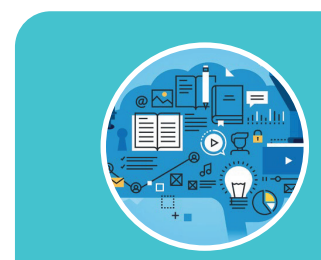

$50 \%$ Doctors found digital platforms to be an effective tool for patient interactions

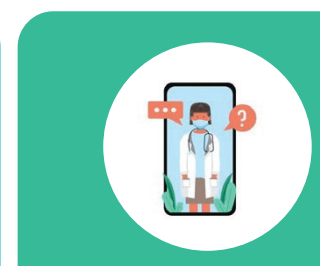

$80 \%$ teleconsultation services were from first-time users

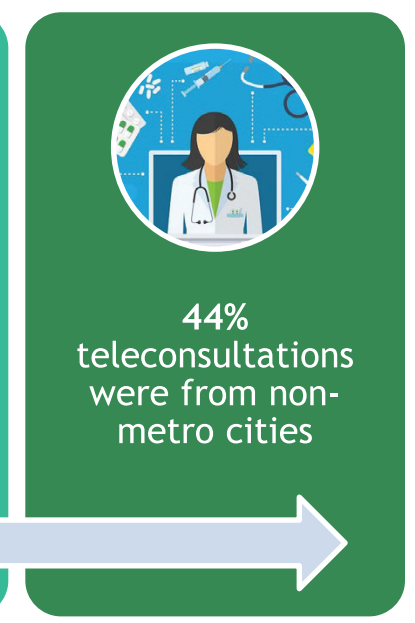

Figure 7: How India Accessed Healthcare During 1 March - 31 May 2020: Digital Healthcare Emerged as a Viable Alternative to Traditional Delivery Models ${ }^{16}$

Note: Survey of 800 physicians conducted by BCG across Metros and Tier 1 cities.

15 Telemedicine market size in India 2010-2025. Statista Research Department. Retrieved January 7, 20201 from https://www.statista. com/statistics/605179/india-telemedicine-market/.

16 Leapfrogging to a Digital Healthcare System: Re-imagining Healthcare for Every Indian. BCG and FICCI. Retrieved December 20,2020 from https://web-assets.bcg.com/54/d0/e906ee464d72a7fdb7254ba3fc11/leapfrogging-to-a-digital-healthcare-system-bcg-ficci.pdf. 


\subsubsection{INVESTMENT OPPORTUNITIES}

A low presence of doctors in semi-urban, rural and remote areas has resulted in limited access to healthcare facilities for large numbers of people. Telemedicine and e-Health are considered to be potential solutions for addressing this lack of access, on account of the extensive smartphone penetration in India and improving mobile connectivity.

A timely 5-minute consultation enabled by telemedicine can save lives and avoid huge downstream costs. Tele-radiology is also an emerging area with several foreign hospitals now active in this space. These hospitals consult Indian experts for providing opinions to patients.

Many hospitals have adopted the PPP route to render services through telemedicine, especially during the COVID-19 pandemic. A developed telemedicine market also has potential for future export of healthcare services.

Affordable and quality healthcare can be enabled by Artificial Intelligence, wearables and other mobile technologies as well as Internet of Things. Digital health can especially improve outcomes for people suffering from multiple co-morbid conditions because of the possibility of remote monitoring of health status and delivery of virtual care services through smartphones and artificial data solutions. This, in fact, could prove to be the next major booming industry in India.

Prior to COVID-19, the health-tech industry was primarily focused on developing wearable gadgets, diagnostics and medicine delivery solutions; facilitating early diagnosis of genetic conditions; treating lifestyle-linked problems like stress and anxiety through remote therapy as well as post-procedure pain alleviation. ${ }^{39}$

Post the pandemic, new opportunities are likely to emerge in the health-tech space, including development of tools for facilitating emergency care, and improvements to medical infrastructure through technology-based optimisation. ${ }^{40}$ For instance, the scope of wearable devices could be expanded to track health conditions. Patient-facing mobile health applications could also be developed, along with enabling greater integration of Al, robots, and blockchain technologies e.g., surgical robots, sensors, remote diagnostics, electronic records and monitoring systems. ${ }^{39,40}$

It is envisaged that the fundamental approach to medicine could change drastically in the years to come with the entire human biology getting represented as data and patterns. Doctors will increasingly be assisted by machine intelligence and eventually, a large number of cases could possibly be handled largely by machines, with only more complicated cases requiring doctor consultations. Given that India has a shortage of qualified doctors, Al Doctor could be a longterm solution, especially in rural and remote areas. A leading NATHEALTH provider engaged with a State Government in a PPP project covering 182 Electronic Urban Primary Healthcare centres (E-UPHCS). ${ }^{34}$ With a footfall of 12,000 on a daily basis, the program has touched 5.2 Million lives over two years and has brought quality healthcare within the reach of all citizens, by significantly leveraging technology. ${ }^{34}$ This model can be replicated in other rural areas with private players. E-ICUs can also be set up in semi-urban and rural areas, and connected to a central monitoring hub. 


\section{REFERENCES}

1. Note on Health and Pharmaceutical Sector. Invest India.

2. Healthcare: The neglected GDP driver. Need for a paradigm shift. KPMG and FICCl. Retrieved January 10, 2021 from http://ficci.in/study-page. asp? spid=20634\&sectorid=18.

3. Final Report of the Expert Group, High-Level Commission on Health Employment and Economic Growth. World Health Organization. Retrieved January 5, 2021 from https://www.who.int/hrh/com-heeg/en/.

4. National Digital Health Mission. Ministry of Health and Family Welfare. Government of India. Retrieved January 11, 2021 from https://ndhm.gov.in/.

5. Ayushman Bharat - Health and Wellness Centre, Ministry of Health and Family Welfare. Government of India. Retrieved February 23, 2021 from https://ab-hwc. nhp.gov.in/.

6. About Pradhan Mantri Jan Arogya Yojana (PM-JAY). National Health Authority. Retrieved December 15, 2020 from https://pmjay.gov.in.

7. Human Resource and Skill Requirements in the Healthcare Sector. NSDC, Ministry of Skill Development \& Entrepreneurship, Government of India. Retrieved January 5, 2021 from https://skillsip.nsdcindia.org/knowledge-products/human-resource-andskill-requirements-health-sector.

8. Note on Home Healthcare. Nidhi Saxena. Founder and CEO, Zoctr.com.

9. Funding Indian healthcare: Catalysing the next wave of growth. PwC India. Retrieved December 16, 2020 from https://www.pwc.in/publications/2017/funding-indianhealthcare-catalysing-the-next-wave-of-growth.html.

10. Financing and Funding Indian Healthcare: Navigating the Turbulent Tide. PwC India. Retrieved December 16, 2020 from https://www.pwc.in/assets/pdfs/publications/2018/ financing-and-funding-indian-healthcare-navigating-the-turbulent-tide.pdf.

11. Hospitals. $\mathrm{ICICl}$ Direct Research. Retrieved January 3, 2021 from http://content. icicidirect.com/mailimages/IDirect_Healthcare_SectorReport.pdf.

12. National Health Policy, 2017. Ministry of Health and Family Welfare. Government of India. Retrieved February 23, 2021 from https://www.nhp.gov.in/nhpfiles/national_ health_policy_2017.pdf.

13. Union Budget. Ministry of Finance. Government of India. Retrieved February 23, 2021 from https://www.indiabudget.gov.in/.

14. Healthcare. India Brand Equity Foundation. Retrieved December 15, 2020 from https://www.ibef.org/download/Healthcare-July-2019.pdf.

15. National Medical Commission. Retrieved 23 February, 2021 from https://www.nmc. org.in/.

16. Healthcare. Invest India. https://www.investindia.gov.in/sector/healthcare.

17. Leapfrogging to a Digital Healthcare System: Re-imagining Healthcare for Every Indian. BCG and FICCl. Retrieved December 20, 2020 from https://web-assets.bcg. 
com/54/dO/e906ee464d72a7fdb7254ba3fc11/leapfrogging-to-a-digital-healthcaresystem-bcg-ficci.pdf.

18. Fact Sheet on Foreign Direct Investment. Department for Promotion of Industry and Internal Trade. Government of India. Retrieved January 5, 2021 from https://dipp. gov.in/sites/default/files/FDI_Factsheet_June20_23Sept2020.pdf.

19. Lucknow Declaration: 1st India Africa Defence Ministers Conclave, 2020. Ministry of External Affairs. Government of India. Retrieved January 15, 2021 from https://mea. gov.in/bilateral-documents.htm?dtl/32378.

20. Note on Health Diplomacy. Ministry of External Affairs. Government of India.

21. AatmaNirbhar Bharat Abhiyan. Government of India. Retrieved January 15, 2021 from https://aatmanirbharbharat.mygov.in/.

22. Guidelines for Forwarding Proposals for Financial Support to Public Private Partnerships in Infrastructure Under the Viability Gap Funding Scheme. Department of Economic Affairs. Ministry of Finance. Government of India. https://dea.gov.in/sites/default/ files/Document\%204\%28i\%29_Guidelines\%2Ofor\%20financial\%20support\%20to\%20 Public\%2OPrivate\%2OPartnership\%2OProjects\%2Oin\%2OInfrastructure\%20under\%20 the\%2OViability\%20Gap\%2OFunding\%20Scheme\%25.pdf.

23. Cabinet approves Continuation and Revamping of the Scheme for Financial Support to Public Private Partnerships in Infrastructure Viability Gap Funding VGF Scheme. PIB Delhi. https://www.pib.gov.in/PressReleasePage.aspx?PRID=1671914.

24. The Indian Pharmaceutical Industry - The Way Forward. Indian Pharmaceutical Alliance. Retrieved December 28, 2020 from https://www.ipa-india.org/static-files/ pdf/publications/position-papers/2019/ipa-way-forward.pdf.

25. Handbook 2020. Pharmaceuticals Export Promotion Council of India. Ministry of Commerce \& Industry. Government of India. Retrieved January 6, 2021 from https:// cdsco.gov.in/opencms/export/sites/CDSCO_WEB/Pdf-documents/NewDrugs_ CTRules_2019.pdf.

26. Domestic Policy Constraints For Exports in Select Sectors. Export-Import Bank of India. https://www.eximbankindia.in/Assets/Dynamic/PDF/Publication-Resources/ SpecialPublications/Report-on-Domestic-Constraints-on-Exports-of-SelectedSectors-new.pdf.

27. Clinical Research. Sector Profile. FICCl. Retrieved December 4, 2020 from http://ficci. in/sector/77/Project_docs/ficci-sector-Clinical_Research.pdf.

28. Strategy for New India @ 75. NITI Aayog. Government of India. Retrieved January 14, 2021 from https://niti.gov.in/the-strategy-for-new-india.

29. BIRAC. Retrieved February 22, 2021 from https://birac.nic.in/.

30. The MedTech Industry in India - COVID-19 and Beyond. PwC. Retrieved January 2, 2021 from https://www.google.co.in/amp/s/www.expresshealthcare.in/amp/news/ covid-19-restricted-access-to-healthcare-in-india-pwc-paper/426681/.

31. Andhra Pradesh MedTech Zone Limited. Government of Andhra Pradesh. Retrieved February 23, 2021 from https://www.amtz.in/. 
32. India: Building Best Practices in Healthcare Services Globally. FICCl. Retrieved January 5, 2021 from http://ficci.in/spdocument/23136/FICCl-EY-Report-on-MVT.pdf.

33. India Tourism Statistics 2019. Ministry of Tourism. Government of India. Retrieved January 2, 2021 from https://tourism.gov.in/sites/default/files/2020-04/India\%20 Tourism\%20Statistics\%202019.pdf.

34. Recommendations to Reinvigorate the Private Health Sector in India. NATHEALTH.

35. Note on Service Tax Issue. NATHEALTH.

36. Telemedicine market size in India 2010-2025. Statista Research Department. Retrieved January 7, 20201 from https://www.statista.com/statistics/605179/indiatelemedicine-market/.

37. Telemedicine Practice Guidelines: Enabling Registered Medical Practitioners to Provide Healthcare Using Telemedicine. Board of Governors. In supersession of the Medical Council of India. Retrieved January 12, 2021 from https://www.mohfw.gov. in/pdf/Telemedicine.pdf.

38. "eSanjeevani" Telemedicine Service Records 1 Million Tele-Consultations. PIB Delhi. Retrieved February 22, 2021 from https://pib.gov.in/PressReleaselframePage. aspx?PRID=1680535.

39. COVID-19 Brings Unprecedented Shifts in Healthcare Technology Adoption. IDTechEX. Retrieved January 14, 2021 from https://www.idtechex.com/en/research-article/covid19-brings-unprecedented-shifts-in-healthcare-technology-adoption/22322.

40. From Wearables To Diagnosis To Telemedicine: India's Healthtech Startups Come Of Age. Inc42. Retrieved January 14, 2021 from https://inc42.com/features/fromcreating-wearables-to-aiding-early-stage-diagnosis-indias-healthtech-startups-comeof-age/. 
